\section{Phosphorylase kinase deficient liver glycogenosis: progression to cirrhosis in infancy associated with PHKG2 mutations (H144Y and L225R)}

EDITOR-Deficiency of phosphorylase kinase (Phk), a regulatory protein kinase in glycogen metabolism, is the most frequent cause of hepatic glycogen storage disease (GSD). Patients typically present as infants with hepatomegaly, growth retardation, and raised triglycerides, cholesterol, and transaminases. Compared to other types of liver GSD, the condition is usually mild and its course is benign such that patients may even become asymptomatic as they grow up. Hypoglycaemia and lactic acidosis, for example, are uncommon in Phk deficiency in contrast to glucose-6-phosphatase deficiency (GSD type I). Hepatic architecture typically remains normal, unlike GSD III (debranching enzyme deficiency) in which hepatic fibrosis is common, and unlike GSD IV (branching enzyme deficiency) which usually progresses to cirrhosis in infancy. Only two infants with Phk deficiency and cirrhosis have been reported. Development of fibrosis and even cirrhosis was found in five older Japanese patients, but it remains to be clarified whether this observation can be generalised and also applies to other ethnic groups..$^{1-5}$

Phk is a complex enzyme consisting of four different subunits, $(\alpha \beta \gamma \delta)_{4}$, and isoforms or splice variants exist for each subunit. This gives rise to genetic and phenotypic heterogeneity of Phk deficiency. ${ }^{6}$ A muscle specific form of Phk deficiency is caused by mutations in the gene for the muscle isoform of the $\alpha$ subunit, PHKA1, which resides on the long arm of the $\mathrm{X}$ chromosome, whereas liver Phk deficiency can be caused by mutations in three genes: PHKA2, $P H K B$, and PHKG2. PHKA2 encodes the liver isoform of the $\alpha$ subunit. It is located on the short arm of the $\mathrm{X}$ chromosome and therefore involved in most (male) cases of liver Phk deficiency. ${ }^{7} P H K B$, located on human chromo- some 16 , encodes the $\beta$ subunit that is expressed in all tissues. PHKB mutations therefore cause autosomal recessive Phk deficiency of both liver and muscle, but liver symptoms predominate and the biochemical muscle involvement is often not clinically apparent. Ten different mutations in the $P H K B$ gene have been identified in seven patients. ${ }^{8-10}$ $P H K G 2$, also autosomal, encodes the testis/liver isoform of the catalytic $\gamma$ subunit. PHKG2 mutations seem to be the rarest variant with only five patients described to date, all of them homozygous offspring of consanguineous parents. ${ }^{11}{ }^{12}$

A genotype-phenotype correlation is emerging in liver Phk deficiency. The functional impact of $P H K B$ mutations, both on residual enzyme activity and clinical condition, appears to be mildest. In contrast, PHKG2 mutations seem to concentrate at the opposite end of the spectrum of severity with very low residual Phk activities, very high plasma lipids and transaminases, and other abnormalities that are uncommon in Phk deficiency, such as lactic acidosis, abnormal glucagon response, or hepatocellular adenoma. Most strikingly, the only two published cases of Phk deficiency who developed liver cirrhosis in infancy were both found to carry translation terminating mutations in the PHKG2 gene. ${ }^{11}{ }^{12}$ In the present study, we have identified PHKG2 mutations in another patient with liver Phk deficiency and early cirrhosis, further substantiating that PHKG2 mutations are associated with a more severe phenotype and particularly with a high risk of cirrhosis.

A male infant, the first child of healthy, unrelated English parents, presented with abdominal distension from 5 months, and three early morning episodes of eye rolling, pallor, and clamminess at 7 months. Examination showed poor growth, muscle wasting, and hepatomegaly $11 \mathrm{~cm}$ below the costal margin. Abnormal findings included low prefeed plasma glucose $(0.5 \mathrm{mmol} / \mathrm{l})$, raised plasma alanine aminotransferase $(587$, normal $<45 \mathrm{U} / 1)$, aspartate aminotransferase (>2000, normal <45 U/1), and $\gamma$-glutamyltranspeptidase $(2150$, normal $<40 \mathrm{U} / 1)$, and raised plasma cholesterol (18.4, normal 2.5-4.4 mmol/l) and triglycerides (9.3, normal $1.5-1.8 \mathrm{mmol} / \mathrm{l})$. Phk activity
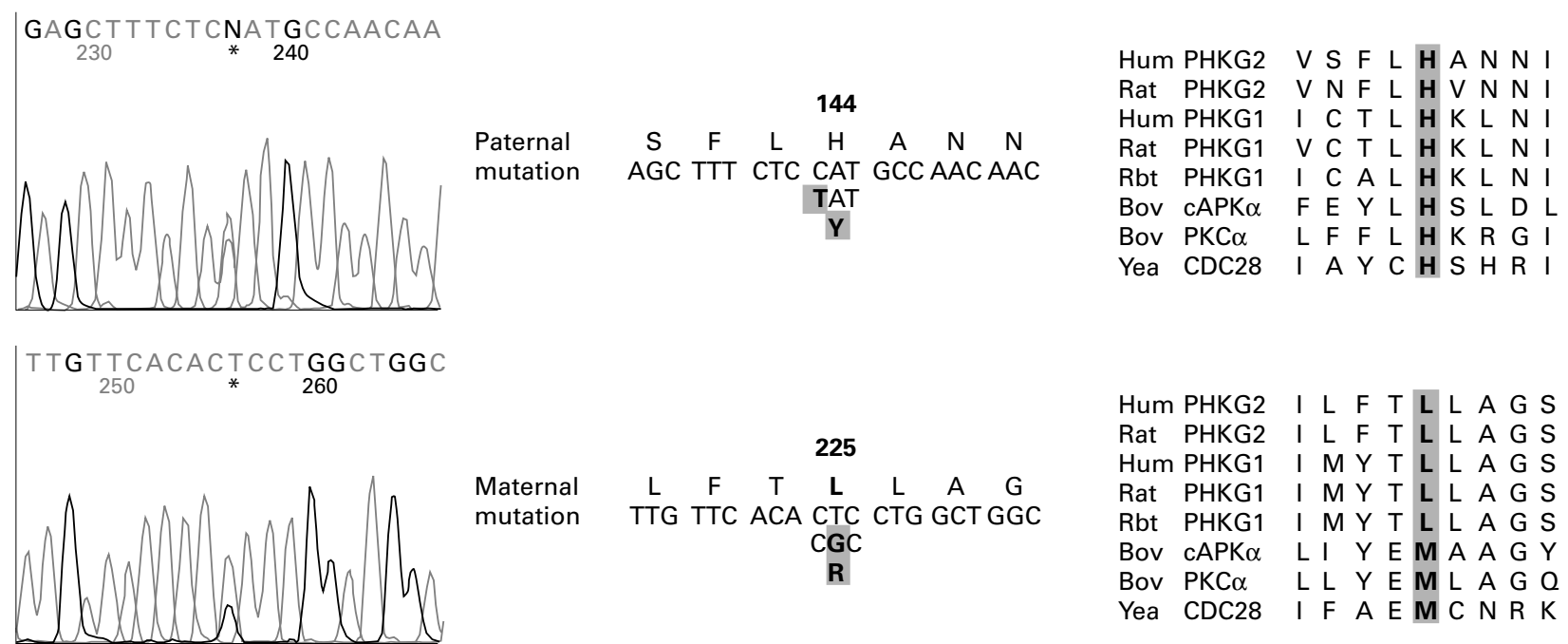

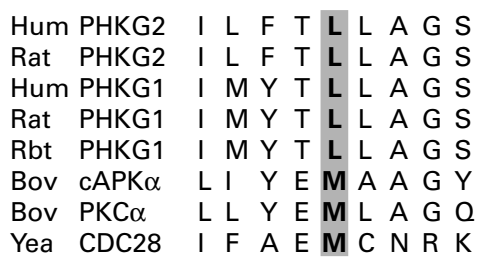

Figure 1 PHKG2 missense mutations in a patient with Phk deficiency and liver cirrhosis. Sequencer tracings are shown on the left, with heterozygous sequence positions marked by asterisks. On the right, the high conservation of the mutated amino acids is illustrated by alignment of the corresponding sequence regions from the testis/liver (PHKG2) and muscle (PHKG1) isoforms of the Phk $\gamma$ subunit from human, rat, and rabbit, and from bovine protein kinase $A$ (a isoform), bovine protein kinase C (a isoform), and yeast CDC28 kinase as examples of other serine/threonine kinases. See refs 11 and 13 for sequence references and alignment of additional protein kinase sequences. 
was $1.6 \mathrm{U} / \mathrm{g} \mathrm{Hb}$ (normal, 6-30) in erythrocytes and <1 U/g wet weight (normal, $>20$ ) in liver. Hepatic branching and debranching enzyme activities were normal. Liver histology showed fibrous expansion of portal tracts with portal-portal bridging and gross parenchymal glycogen deposition with minimal fat. Overnight nasogastric feeds and two-hourly daytime feeds were necessary to prevent hypoglycaemia and lactic acidosis. Firm irregular hepatomegaly and raised plasma transaminases persisted. Repeat liver biopsy at 3 years showed that glycogen deposition had diminished but cirrhosis was present, with broad bands of interportal fibrosis encircling parenchymal nodules.

Genomic DNA was purified from a blood sample and the PHKG2 gene amplified in four segments and analysed by direct sequencing in both directions, as described previously. ${ }^{12}$ The patient was found to be heterozygous for two single nucleotide replacements: a $\mathrm{C}$ to $\mathrm{T}$ transition replacing histidine 144 with tyrosine, and a $T$ to $G$ transversion replacing leucine 225 with arginine (fig 1 ). $\mathrm{H} 144$ is not only conserved in both Phk $\gamma$ subunit isoforms from several species, but also in the catalytic domains of nearly all serine/threonine protein kinases, where it resides in subdomain VI A. ${ }^{13}$ Similarly, the counterparts of L225 in more than 100 protein kinase sequences (subdomain IX) are most frequently leucines, methionines, or other hydrophobic or uncharged amino acids, but never charged residues (fig 1). ${ }^{13}$ Analysis of parental DNA showed that the $\mathrm{H} 144 \mathrm{Y}$ allele had been inherited from the father and the L225R allele from the mother, together accounting for the patient's enzyme deficiency.

The patient described here is the first male case and the first to be found compound heterozygous for PHKG2 mutations, whereas all previous $P H K G 2$ cases were female, homozygous offspring of consanguineous parents. All seven PHKG2 mutations identified to date in different subjects are unique. Including the patient described here, three liver Phk deficiency cases with early cirrhosis have now been analysed for mutations, and PHKG2 mutations were identified in all three. This suggests strongly that this rare complication of Phk deficient liver glycogenosis is generally caused by PHKG2 mutations. Among the first group of three other patients not selected for clinical severity in which PHKG2 mutations were identified, one had a mild course whereas two developed fibrosis but not cirrhosis at an early age together with other complications uncommon in Phk deficiency. ${ }^{11} \mathrm{~A}$ feature shared by all previous cases and the present one is a very low residual Phk activity and pronounced secondary biochemical abnormalities. Missense as well as truncating mutations are found among both the cirrhotic and the non-cirrhotic patients, so that no obvious correlation between mutation severity and cirrhosis is evident. These observations suggest that patients with PHKG2 mutations have a much higher risk of severe liver disease than those with PHKA2 or PHKB mutations. The malignant potential of cirrhosis in this small subgroup is unknown.

We thank Dr S K Hanumara for referring the case and Dr S Variend for histology. This work was supported by grants from the Deutsche Forschungsgemeinogy. This work was supported by grants from the
schaft and the Fonds der Chemischen Industrie.

\section{BARBARA BURWINKEL *} $M$ STUART TANNER $†$ MANFRED W KILIMANN*

^Institut für Physiologische Chemie, Ruhr-Universität Bochum, D-44780 Bochum, Germany

†The Sheffield Children's Hospital, University of Sheffield, Division of Child Health, Sheffield S10 2TH, UK

Correspondence to: Dr Kilimann, manfred.kilimann@ruhr-uni-bochum.de

1 Chen YT, Burchell A. Glycogen storage diseases. In: Scriver CR, Beaudet AL, Sly WS, Valle D, eds. The metabolic and molecular bases of inherited disease. 7 th ed. Vol 1. New York: McGraw-Hill, 1995:935-65.

2 Willems PJ, Gerver WJM, Berger R, Fernandes J. The natural history of liver glycogenosis due to phosphorylase kinase deficiency: a longitudinal study of 41 patients. Eur f Pediatr 1990;149:268-71.

3 Shiomi S, Saeki Y, Kim K, et al. A female case of type VIII glycogenosis who developed cirrhosis of the liver and hepatocellular tumor. Gastroenterol fpn 1989;24:711-14.

4 Kagalwalla AF, Kagalwalla YA, Al Ajaji S, Gorka W, Ali MA. Phosphorylase b kinase deficiency glycogenosis with cirrhosis of the liver. F Pediatr 1995; 127:602-5

5 Aikawa J, Ohura T, Inuma K, Narisawa K. Management of phosphorylase kinase deficiency - outcome and control of phosphorylase kinase deficiency. f Inherit Metab Dis 1997;20:84.

6 Kilimann MW. Glycogen storage disease due to phosphorylase kinase deficiency. In: Swallow DM, Edwards YH, eds. Protein dysfunction and human genetic disease. Oxford: BIOS Scientific Publishers, 1997:57-75.

7 Burwinkel B, Amat L, Gray RGF, et al. Variability of biochemical and clinical phenotype in X-linked liver glycogenosis with mutations in the phosphorylase kinase PHKA2 gene. Hum Genet 1998;102:423-9.

8 Burwinkel B, Maichele AJ, Aagenes Ö, et al. Autosomal glycogenosis of liver and muscle due to phosphorylase kinase deficiency is caused by mutations in the phosphorylase kinase $\beta$ subunit $(P H K B)$. Hum Mol Genet in the phosphory

9 van den Berg IET, van Beurden EACM, de Klerk JBC, et al. Autosomal recessive phosphorylase kinase deficiency in liver, caused by mutations in the gene encoding the $\beta$ subunit $(P H K B)$. Am f Hum Genet 1997;61:539-46.

10 Burwinkel B, Moses SW, Kilimann MW. Phosphorylase-kinase-deficient liver glycogenosis with an unusual biochemical phenotype in blood cells associated with a missense mutation in the $\beta$ subunit gene (PHKB). Hum Genet 1997;101:170-4.

11 Maichele AJ, Burwinkel B, Maire I, Sövik O, Kilimann MW. Mutations in the testis/liver isoform of the phosphorylase kinase $\gamma$ subunit (PHKG2) cause autosomal liver glycogenosis in the gsd rat and in humans. Nat Genet 1996;14:337-40

12 Burwinkel B, Shiomi, S, Al-Zaben A, Kilimann MW. Liver glycogenosis due to phosphorylase kinase deficiency: PHKG2 gene structure and mutations associated with cirrhosis. Hum Mol Genet 1998;7:149-54.

13 Hanks SK, Quinn AM. Protein kinase catalytic domain sequence database: identification of conserved features of primary structure and classification of family members. Methods Enzymol 1991;200:38-62.
EDITOR-Familial Wilms tumour is rare, accounting for only $1-2 \%$ of cases, and is not usually associated with other tumour types or congenital malformation. ${ }^{1}$ The pattern of inheritance has been interpreted as a dominant predisposition to Wilms tumour with incomplete penetrance of approximately $30 \%$. Following the isolation of the WT1 gene in 1990, it soon became clear that WT1 mutation did not account for any of the large Wilms tumour pedigrees and was found in only the minority $(\sim 10 \%)$ of sporadic

\section{Familial Wilms tumour resulting from WT1 mutation: intronic polymorphism causing artefactual constitutional homozygosity}

Wilms tumours. Pedigree specific differences in age at onset, incidence of bilateral tumours, and presence of metastases provided further evidence for the existence of more than one gene for familial Wilms tumour. ${ }^{1}$ Recently, two familial Wilms tumour gene loci, designated FWT1 and $F W T 2$, have been mapped by genetic linkage analysis to $17 \mathrm{q} 12-21$ and $19 \mathrm{q}$ respectively. ${ }^{23}$

While a series of Wilms tumour families were being analysed for linkage to the putative FWT1 locus on $17 \mathrm{q},{ }^{2}$ one proband was noted to carry a tumour specific $11 \mathrm{p} 13$ deletion (the WT1 locus) and to suffer from genitourinary abnormalities (fig 1). Mutational analysis of WT1 was therefore undertaken in this pedigree.

Family WILMS 5 was identified as a sib pair affected with unilateral Wilms tumour. The sister (No 301) presented at the age of 2 years with a tumour of fetal rhabdomyomatous type and remains well 12 years later. Her brother (No 302) presented at the age of 4 years with a 


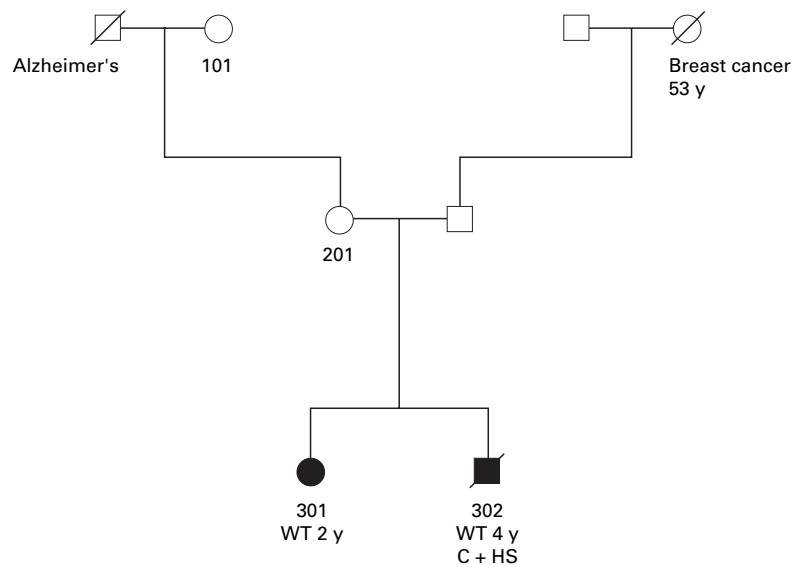

Figure 1 Pedigree of WILMS 5. WT = Wilms tumour, $C+H S=$ cryptorchidism and hypospadias. Subjects 201,301, and 302 are carriers of an intragenic WT1 mutation. 101 is not a carrier. It is unknown whether the mutation arose in 201 de novo or was inherited from her father. However, none of her three sibs nor any of their eight offspring were affected by Wilms tumour.

tumour of biphasic histology (stromal and blastemal). $\mathrm{He}$ relapsed shortly after finishing standard treatment and subsequently died from progressive tumour. He suffered from severe bilateral cryptorchidism and hypospadias, and surgery showed the presence of persistent Mullerian structures as well as testicular tissue. His constitutional karyotype was 46,XY whereas metaphases from the tumour displayed an interstitial $11 \mathrm{p} 13$ deletion and an isochromosome 1q. Both parents were phenotypically normal with no history of Wilms tumour. There was no family history of other cancers or congenital malformation.

Sequencing of exon 7 of WT1, which codes for the first zinc finger, showed a heterozygous $7 \mathrm{bp}$ deletion in constitutional DNA from both affected sibs. This frameshift is predicted to lead to the introduction of 59 novel amino acids following $\mathrm{Ser}^{318}$ with a termination codon before the zinc finger region, which is known to be critical for DNA binding by this putative transcription factor. Sequencing of the remaining exons showed no other mutations. Tumour DNA from 302 had only the mutant allele, as expected, since the tumour karyotype showed an interstitial deletion of $11 \mathrm{p} 13$. Tumour DNA from 301 showed an intragenic mutation of the second WT1 allele, a $26 \mathrm{bp}$ insertion also in exon 7, predicted to introduce a termination codon after two novel amino acids. Thus, in both sibs' tumours, WT1 was behaving as a tumour suppressor gene, with loss of function mutations affecting both alleles.

Sequencing of lymphocyte DNA from the mother (No 201), who is phenotypically normal, showed homozygosity for the $7 \mathrm{bp}$ deletion. This was an unexpected finding, since homozygous constitutional mutation of WT1 in a murine knock out model causes absence of the kidneys and gonads and is incompatible with postnatal survival. ${ }^{4}$ However, a single case of a Japanese girl with Denys-Drash syndrome (DDS), who is constitutionally homozygous for a missense mutation in zinc finger 2 has been described. ${ }^{5}{ }^{6}$ Her viability, in contrast to the prediction of the knock out model, may be because of the presence of a mutant form of WT1, still capable of protein-protein interactions. The truncated WT1 protein produced in the WILMS 5 pedigree could also be capable of such activity through its N-terminal region. An alternative explanation is species specific differences in requirements for WT1 function.

Further investigations were therefore carried out to resolve this discrepancy. DNA extracted from buccal cells and from skin fibroblasts exhibited the same homozygous genotype, ruling out the possibility of constitutional mosaicism. However, PCR analysis using a new primer set external to the original pair showed that subject 201 was in
A

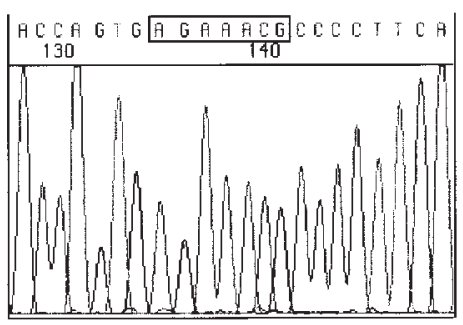

Normal WT1 sequence

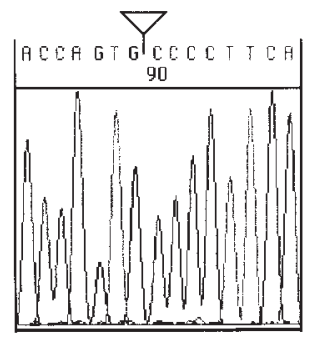

Sequence from subject 201 using primer pair $1 \mathrm{~F}$ and $1 \mathrm{R}$

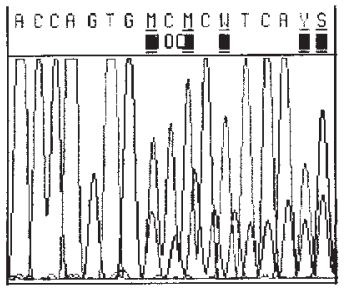

Sequence from subject 201 using primer pair $2 \mathrm{~F}$ and $2 \mathrm{R}$

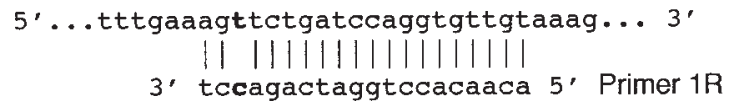

Figure 2 (A) Automated sequencing in the region of the deletion found in family WILMS 5. Top panel, normal sequence, showing the $7 \mathrm{bp}$ that are deleted (boxed). Centre panel, sequence from subject 201 using primer pair 1 , showing apparent homozygosity for the $7 \mathrm{bp}$ deletion. Lower panel, sequence from subject 201 using primer pair 2, showing heterozygosity for the $7 \mathrm{bp}$ deletion. (B) Sequence of the intron downstream of exon 7 from subject 201 around the annealing site for primer $1 R$. The mismatch at the $3^{\prime}$ end of the primer is shown in bold. Mutational analysis for exons 1-10 of WT1 was performed on DNA extracted from blood, buccal cells (201 only), and tumour material (301 and 302) as previously described. ${ }^{11}$ Primer sequences for exon 7 were: pair $11 F$ 5'- GACCTACGTGAATGATCACATG -3' and 1R 5'-ACAACACCTGGATCAAGACCT-3'; pair 2 (flanking primer pair 1) $2 F$ 5'-CACCCCTTCTTTGGATATAC -3'and 2R 5'-

CTGACCTCTGTAATAAAGGAT -3'. PCR conditions for primer pair 2 (449 bp product) were $1.5 \mathrm{mmol} / \mathrm{l} \mathrm{MgCl}_{2}, 55^{\circ} \mathrm{C}$ annealing. PCR products were sequenced using the ABI Prism Dye Terminator Cycle Sequencing kit with AmpliTaq FS using a modified method and capillary electrophoresed on a 310 Genetic Analyser (Perkin Elmer ABI)..$^{15}$ The results were analysed using Factura software and by eye to identify heterozygotes. Samples containing mutations were resequenced using a second independent PCR product as a template. Subcloning and sequencing of PCR products was carried out as previously described, where necessary. ${ }^{11}$

fact constitutionally heterozygous for the deletion. The apparent homozygosity was the result of an intronic point mutation, close to the 3' end of the original reverse primer, preventing amplification of the normal allele (fig 2). This base change was also found in the maternal grandmother (subject 101). No material was available from the maternal grandfather so it was not possible to say whether the inherited WT1 mutation had arisen de novo in subject 201 or was paternally inherited. Since primer pair 1 had been used in our previous screen for WT1 mutations in leukaemia, a small study was undertaken to see if this intronic base 
change was common. Constitutional DNA from 16 normal people and two with Wilms tumours was sequenced, but none was found to carry the $G$ to $T$ change, implying that this base change is either a rare polymorphism or is specific to family WILMS 5. This illustrates the importance of verifying homozygous constitutional mutations using a second pair of PCR primers or an independent method.

This is only the fourth Wilms tumour pedigree where an inherited WT1 mutation has been identified. In the previously described pedigrees, one combined familial Wilms tumour with aniridia owing to transmission of a $\mathrm{t}(2 ; 11)(\mathrm{q} 32 ; \mathrm{p} 13)$ with presumed complete deletion of the adjacent WT1 and PAX6 genes at $11 \mathrm{p} 13 .^{7} \mathrm{~A}$ father and son both had Wilms tumour associated with a constitutional 1 bp deletion in exon 6 of WT1, causing truncation of the protein before the zinc finger region. ${ }^{8}$ Only the son had urogenital abnormalities. In the third family, a nonsense mutation in zinc finger 2 was transmitted by an unaffected father to three daughters all affected by Wilms tumour. ${ }^{9}$ The same mutation has also been reported in a person with Denys-Drash syndrome but there were no features of this syndrome in this pedigree. ${ }^{10}$

The mutation described in the pedigree in this report is novel, although mutations resulting in truncation of $W T 1$ in exons 6 or 7, just before the zinc finger region, are described in sporadic Wilms tumours and in acute myeloid leukaemia. ${ }^{11}$ In this pedigree, germline WT1 mutation was associated with severe genitourinary malformation in the male whereas the two females had normal development; the mother is clearly fertile and the daughter has gone through normal puberty. A similar sex difference in severity of genital malformation is seen in patients with Denys-Drash syndrome, now that the syndrome has been expanded to include genotypic females with the characteristic nephropathy and Wilms tumour. This pedigree also shows the variable nature of tumour behaviour resulting from a common initiating event.

It has been suggested that there is a genotype-phenotype correlation in the histological appearance of Wilms tumours with WT1 mutations, with a predominance of differentiation into heterologous mesodermal derivatives, commonly muscle, cartilage, bone, or fat. ${ }^{12}$ Subject 301's Wilms tumour did indeed show an extreme form of heterologous differentiation towards muscle, with the fetal rhabdomyomatous subtype. However, her brother's tumour had biphasic histology (stromal and blastemal) with no heterologous differentiation. This difference may be because of the nature or timing of the second WT1 mutation during renal or tumour development. However, it is equally likely that different morphologies result from an identical initiating mutation owing to the inherent plasticity of renal development. This is clearly seen in Wilms tumours resulting from mutation in the FWT1 gene, where histologies range from classical triphasic Wilms to the fetal rhabdomyomatous subtype (Rahman and Pritchard-Jones, unpublished observations).

Germline WT1 mutations are also found in cases of Wilms tumour without a family history. The greatest number has been described in patients with DDS, but a few have been described in some patients with bilateral tumours or genitourinary abnormalities, particularly cryptorchidism, and in a small number of unilateral cases without congenital abnormalities. ${ }^{12-14}$ In a few of these cases, the mutation is inherited from an unaffected parent. Germline mutations causing truncations in exon 7 of WT1 have been described in four patients with sporadic Wilms tumour, all of whom had normal genitourinary development. ${ }^{12}$ This is in contrast with the severe abnormalities found in subject 302 and further indicates the extreme variability in phenotypic expression of WT1 mutations.
Given the excellent survival following treatment for Wilms tumour without the need for gonadotoxic chemotherapy, the rarity of familial WT1 mutation could be because of pleiotropic effects of germline WT1 on genitourinary development, causing reduced fertility in affected subjects. Constitutional WT1 mutations are more commonly found in certain congenital malformation syndromes predisposing to childhood genitourinary cancers (WAGR, Denys-Drash syndrome, and Frasier syndrome). Nevertheless, sporadic Wilms tumours occurring in conjunction with genitourinary abnormalities or showing heterologous differentiation can be the result of germline WT1 mutations. Screening of such patients and their relatives is advisable, particularly as unaffected subjects can carry mutations that might have severe consequences for their offspring. Ten of 21 patients with Wilms tumours showing heterologous differentiation had germline WT1 mutations. ${ }^{12}$ A recent report by the National Wilms Tumour Study Group found germline WT1 mutations in $7 / 28$ Wilms tumour patients with cryptorchidism and 4/12 with hypospadias, but only $1 / 110$ patients without genitourinary malformation. ${ }^{13}$ WT1 mutational screening can therefore probably be safely reserved for cases selected on the basis of associated abnormalities or tumour histology.

We thank Dr A M Potter, Centre for Human Genetics, Sheffield, for tumour cytogenetic data and Dr V Murday, St George's Hospital, for culturing the skin biopsy on subject 201. KPJ and LKU are supported by the Cancer Research Campaign and the Royal Marsden Children's Cancer Unit Fund.

KATHY PRITCHARD-JONES* NAZNEEN RAHMAN† MARY GERRARD $\ddagger$ DICK VARIEND\$

LINDA KING-UNDERWOOD

* Section of Paediatric Oncology, Institute of Cancer Research, 15 Cotswold Road, Belmont, Sutton, Surrey SM2 5NG, UK

†Section of Cancer Genetics, Institute of Cancer Research, Sutton, Surrey, UK $\ddagger$ Sheffield Children’s Hospital NHS Trust, Western Bank, Sheffield, $S 102 T H, U K$

\Department of Histopathology, Sheffield Children's Hospital NHS Trust, Sheffield, UK

ๆSection of Paediatric Oncology, Institute of Cancer Research, Sutton, Surrey, UK

1 Breslow NE, Olson J, Moksness J, Beckwith JB, Grundy P. Familial Wilms' tumor: a descriptive study. Med Pediatr Oncol 1996;27:398-403.

2 Rahman N, Arbour L, Tonin P, et al. Evidence for a familial Wilms' tumour Rane (FWT1) on chromosome 17q12-q21. Nat Genet 1996;13:461-3.

3 McDonald JM, Douglass EC, Fisher R, et al. Linkage of familial Wilms' tumor predisposition to chromosome 19 and a two-locus model for the etitumor predisposition to chromosome 19 and a two-loc
ology of familial tumors. Cancer Res 1998;58:1387-90.

ology of familial tumors. Cancer Res 1998;58:1387-90.
4 Kreidberg JA, Sariola H, Loring JM, et al. WT-1 is required for early kidney development. Cell 1993;74:679-91.

5 Sakai A, Tadokoro K, Yanagisawa $\mathrm{H}$, et al. A novel mutation of the WT1 gene (a tumor suppressor gene for Wilms' tumor) in a patient with DenysDrash syndrome. Hum Mol Genet 1993;2:1969-70.

6 Kikuchi H, Akasaka Y, Kurosawa Y, Yoneyama H, Kato S, Hata J. A critical mutation in both WT1 alleles is not sufficient to cause Wilms' tumor. FEBS Lett 1995;360:26-8.

7 Yunis JJ, Ramsay NK. Familial occurrence of the aniridia-Wilms tumor syndrome with deletion 11p13-14.1. F Pediatr 1980;96:1027-30.

8 Pelletier J, Bruening W, Li FP, Haber DA, Glaser T, Housman DE. WT1 mutations contribute to abnormal genital system development and hereditary Wilms' tumour. Nature 1991;353:431-4.

9 Kaplinsky C, Ghahremani M, Frishberg Y, Rechavi G, Pelletier J. Familial Wilms' tumor associated with a WT1 zinc finger mutation. Genomics 1996; Wilms' tu

10 Little $\mathrm{MH}$, Williamson KA, Mannens $\mathrm{M}$, et al. Evidence that WT1 mutations in Denys-Drash syndrome patients may act in a dominantnegative fashion. Hum Mol Genet 1993;2:259-64.

11 King-Underwood L, Pritchard-Jones K. Wilms' tumor (WT1) gene mutations occur mainly in acute myeloid leukemia and may confer drug resistance. Blood 1998;91:2961-8.

12 Schumacher V, Schneider S, Figge A, et al. Correlation of germ-line mutations and two-hit inactivation of the WT1 gene with Wilms tumors of stromal-predominant histology. Proc Natl Acad Sci USA 1997;94:3972-7.

13 Diller L, Ghahremani M, Morgan J, et al. Constitutional WT1 mutations in Wilms' tumor patients. F Clin Oncol 1998;16:3634-40.

14 Little M, Wells C. A clinical overview of WT1 gene mutations. Hum Mutat 1997;9:209-25.

15 Lens D, DeSchouwer PJJC, Hamoudi RA, et al. p53 abnormalities in B-cell prolymphocytic leukemia. Blood 1997;89:2015-23. 


\section{Silver-Russell syndrome and ring chromosome 7}

EDITOR-We read the recent paper by Miyoshi et al ${ }^{1}$ with great interest. They report a child with Silver-Russell syndrome (SRS) and maternal uniparental disomy of chromosome 7 (mUPD7), with 30\% mosaicism for an additional ring chromosome 7 of paternal origin. As the ring contained four CA repeat polymorphic markers which map to the region 7p13-q11 (D7S2552, D7S499, D7S494, and D7S2503), they concluded that imprinted genes within this region can be ruled out as candidates for SRS. While the data are interesting, we feel that they are inadequate to support this conclusion.

Firstly, the genetic distance spanned by the four markers used to define the extent of biparental inheritance is small (2.26 $\mathrm{cM}$ between 64.81 and $67.07 \mathrm{cM}$ ). ${ }^{2}$ Furthermore, UPD was shown using marker D7S506 which is estimated to lie less than $0.1 \mathrm{cM}$ distal to D7S2552. The trisomic region is therefore likely to be considerably smaller than 7p13-q11. There are now more accurate localisations for at least two of the biparentally inherited markers; D7S499 and D7S494 have been mapped to 7p11.2 and 7p11.2q11.1, respectively. ${ }^{3}$ The ring may therefore only include a small region close to the centromere, leaving $7 \mathrm{p} 12-13$ uninvolved. It is interesting to note that three genes (IGFBP1, IGFBP3, and GRB10), which have been proposed as candidates for SRS, ${ }^{45}$ lie between two markers (D7S2497 and D7S506) which are outside the potentially excluded region.

There is also no evidence to show that genes on the ring chromosome are active. Indeed, follow up of patients with supernumerary marker chromosomes has found that they are frequently not associated with any phenotypic effect. ${ }^{6}$ Finally, even if the ring chromosome is active, it can only be used to infer exclusion of a paternally expressed imprinted gene from the region. If the SRS gene is transcribed exclusively from the maternal allele, it will be overexpressed in this patient, whether or not the gene is located within the ring chromosome, since she has mUPD7.

In conclusion, caution should be used not to overinterpret the data reported by Miyoshi et al. ${ }^{1}$ Nevertheless, the findings do support the continuing search for a candidate imprinted gene(s) for SRS on chromosome 7. They also emphasise the importance of searching for cytogenetic abnormalities of chromosome 7 in SRS which will provide much needed clues to the region involved.

EMMA L WAKELING*+ MEGAN HITCHINS* $†$ PHILIP STANIER ${ }^{\star}$ DAVID MONK*

GUDRUN E MOORE* MICHAEL A PREECE* ${ }^{\star}$

*Action Research Laboratory for the Molecular Biology of Fetal Development, Division of Paediatrics, Obstetrics and Gynaecology, Imperial College School of Medicine, Queen Charlotte's and Chelsea Hospital, Goldhawk Road, London W6 OXG, UK

†Biochemistry, Endocrinology and Metabolism Unit, Institute of Child Health, University College London, 30 Guilford Street, London WC1N 1EH, UK

Correspondence to: Professor Preece, mpreece@ich.ucl.ac.uk

This letter was shown to Dr Miyoshi et al, who reply as follows.

Dr Wakeling et al suggest that the ring chromosome 7 observed in our SRS patient must be smaller than we estimated. This is based on databases ${ }^{2}{ }^{3}$; for example, the genetic distance between markers D7S506 and D7S2552 they cite is $<0.1 \mathrm{cM}$. However, when using another database, ${ }^{7}$ it is calculated to be $1.1 \mathrm{cM}$. Since this discrepancy is obviously derived from the different databases used, and since not many DNA markers have physically been assigned to the chromosomal region, we tried to perform FISH mapping of D7S506, which is the most centromeric marker among those showing UPD(7)mat in our previous study, ${ }^{1}$ using a PAC clone (303F13) containing the marker as a probe. Consequently, the PAC was mapped to the $7 \mathrm{p} 11.1-\mathrm{p} 11.2$ region. This finding indicates that the four biparentally inherited markers (D7S2552, D7S499, D7S494, and D7S2503) we identified ${ }^{1}$ are located centromerically to D7S506 and the short arm breakpoint of the ring chromosome must lie between them. In addition, FISH analysis using a probe for the elastin gene locus (VYSIS, UK) that was localised to $7 \mathrm{q} 11.23$ gave no fluorescence signals on the ring chromosome. Therefore, the extent of the ring is smaller than the $7 \mathrm{p} 11.2-\mathrm{q} 11.23$ segment.

\footnotetext{
1 Miyoshi O, Kondoh T, Taneda H, Otsuka K, Matsumoto T, Niikawa N. $47, \mathrm{XX}, \mathrm{UPD}(7) \mathrm{mat},+\mathrm{r}(7) \mathrm{pat} / 46, \mathrm{XX}, \mathrm{UPD}(7)$ mat mosaicism in a girl with Silver-Russell syndrome (SRS): possible exclusion of the putative SRS gene from a 7p13-q11 region. F Med Genet 1999;36:326-9.

2 http://cedar.genetics.soton.ac.uk/pub/chrom7/map.html

3 Tsui LC, Donis-Keller H, Grzeschik KH Report of the Second International Workshop on Human Chromosome 7 Mapping. 1994; http:// International Workshop on Human Chromosome $7 \mathrm{M}$
www.genlink.wustl.edu/workshops/chr7/7.report.html

4 Preece MA, Price SM, Davies V, et al. Maternal uniparental disomy 7 in Preece MA, Price SM, Davies V, et al. Maternal unip
Silver-Russell syndrome. 7 Med Genet 1997;34:6-9.

Silver-Russell syndrome. F Med Genet 1997;34:6-9.
5 Miyoshi N, Kuroiwa Y, Kohda T, et al. Identification of the Meg1/Grb10 Miyoshi N, Kuroiwa Y, Kohda T, et al. Identification of the Meg1/Grb10
imprinted gene on mouse proximal chromosome 11, a candidate for the imprinted gene on mousell syndrome gene. Proc Natl Acad Sci USA 1998;95:1102-7.

6 Warburton D. De novo balanced chromosome rearrangements and extra marker chromosomes identified at prenatal diagnosis: clinical significance and distribution of breakpoints. Am F Hum Genet 1991;49:995-1013.

7 A new gene map of the human genome, http://www.ncbi.nlm.nih.gov/ genemap98
}

\section{Variants of STAT6 (signal transducer and activator of transcription 6 ) in atopic asthma}

EDITOR-Atopy is characterised by raised IgE levels and it underlies the clinical disorder bronchial asthma. ${ }^{1-3}$ IL-4 and IL-13 play a key role in the development of asthma acting through the IL-4 receptor (IL-4R) and IL-13R, respectively. ${ }^{1-3}$ Since these two receptors share the IL-4R $\alpha$ chain, this subunit is the crucial component required for IL-4 and IL-13 signalling. ${ }^{1-3}$ Recently, three coding variants in the human $I L 4 R$ gene have been identified and these showed genetic and functional association with atopic asthma in different ethnic groups. The Ile 50 variant was associated with atopic asthma in a Japanese population $^{45}$ and Arg551 or Pro478 were associated with IgE levels in American ${ }^{6}$ and German populations, ${ }^{7}$ respectively, but perhaps through different mechanisms. Ile50 specifically and strongly upregulates cellular IgE synthesis through stat6 when tested by cDNA transfection into human and murine $\mathrm{B}$ cell lines. ${ }^{45}$ Functional assay of 
Table 1 Association between variant of STAT6 gene and atopic asthma in the British population

\begin{tabular}{llllll}
\hline & \multicolumn{5}{l}{ 2964G/A genotype of STAT6 } \\
\cline { 3 - 6 } Phenotype & $\begin{array}{l}\text { No of } \\
\text { cases }\end{array}$ & $\begin{array}{l}A A+ \\
A G\end{array}$ & $G G$ & $\begin{array}{l}\text { Odds } \\
(95 \% \text { CI })\end{array}$ & p value \\
\hline Controls & 150 & 62 & 88 & & \\
Atopic asthmatics & 150 & 57 & 93 & $1.15(0.72-1.82)$ & 0.555 \\
Non-asthmatics & 119 & 51 & 68 & & \\
Asthmatics & 181 & 70 & 111 & $1.19(0.74-1.90)$ & 0.470 \\
Low IgE <120 IU/ml & 167 & 63 & 104 & & \\
High IgE $>120 \mathrm{IU} / \mathrm{ml} 1$ & 133 & 58 & 75 & $0.78(0.49-1.25)$ & 0.302 \\
ASE(-) & 110 & 50 & 60 & & \\
ASE(+) & 190 & 71 & 119 & $1.40(0.87-2.25)$ & 0.169 \\
Non-atopics & 99 & 43 & 56 & & \\
Atopics & 201 & 78 & 123 & $1.21(0.74-1.97)$ & 0.442 \\
\hline
\end{tabular}

Table 2 Association between variant of STAT6 gene and atopic asthma in the fapanese population

\begin{tabular}{|c|c|c|c|c|c|}
\hline \multirow[b]{2}{*}{ Phenotype } & \multirow[b]{2}{*}{$\begin{array}{l}\text { No of } \\
\text { cases }\end{array}$} & \multicolumn{4}{|c|}{ 2964G/A genotype of STAT6 } \\
\hline & & $\begin{array}{l}A A+ \\
A G\end{array}$ & $G G$ & $\begin{array}{l}\text { Odds } \\
(95 \% \text { CI) }\end{array}$ & $p$ value \\
\hline Controls & 00 & 91 & 9 & & \\
\hline \multicolumn{6}{|l|}{ Asthma } \\
\hline Adult atopic marked & 100 & 84 & 16 & $1.93(0.79-4.69)$ & 0.134 \\
\hline Adult atopic mild & 100 & 76 & 24 & $3.19(1.40-7.08)$ & 0.0043 \\
\hline Childhood atopic marked & 100 & 90 & 10 & $1.12(0.42-2.93)$ & 0.809 \\
\hline Intrinsic adult & 100 & 88 & 12 & $1.65(0.68-4.00)$ & 0.376 \\
\hline Low IgE & 265 & 224 & 41 & & \\
\hline High IgE & 235 & 204 & 31 & $0.83(0.50-1.37)$ & 0.469 \\
\hline $\operatorname{ASE}(-)$ & 183 & 159 & 24 & & \\
\hline $\operatorname{ASE}(+)$ & 317 & 270 & 47 & $0.87(0.51-1.47)$ & 0.597 \\
\hline Non-atopic & 167 & 147 & 20 & & \\
\hline Atopic & 333 & 278 & 55 & $0.77(0.44-1.31)$ & 0.180 \\
\hline
\end{tabular}

Arg551Gln IL-4R $\alpha$ showed impaired binding of the negative regulatory molecule, protein tyrosine phosphatase, SHP-1, and increased expression of CD23 was found in peripheral blood mononuclear cells after challenge with human IL-4. ${ }^{6}$ However, this finding was not replicated by another group. ${ }^{8}$ In contrast, Pro478 is in tight linkage disequilibrium with $\operatorname{Arg} 551$ in a German population and may change the structure of the receptor, leading to altered phosphorylation patterns of signal molecules and hence lower IgE levels. ${ }^{7}$ These findings emphasise the genetic heterogeneity of atopy and question whether the molecular interaction between variants of IL- $4 \mathrm{R} \alpha$ and its associated signal transduction molecules, such as stat6, may be important..$^{1-3}$

The Stats are a family of transcription factors evolutionarily conserved from Drosophila to humans. ${ }^{9}$ To date seven different STAT genes have been identified in humans. ${ }^{9}$ Stat6 activation correlates with functional responses induced by IL- 4 and IL-13. ${ }^{1-3}$ Mice deficient in Stat6 lack IgE production and Th2 inflammatory reactions. ${ }^{10}{ }^{11}$ Stat 6 is therefore an essential molecule for IL-4 and IL-13 signal transduction. Moreover, it is assigned to chromosome 12q13-14, the site of genetic linkage to atopic asthma.

The aim of this study was to test whether variants of the STAT6 gene relate to atopic asthma in both British $(n=300)$ and Japanese $(n=400)$ populations.

For the Japanese study, 100 adults from Osaka were randomly selected as controls from clients of a commercial medical examination company, with adjustment for the sex and age distribution of this area. ${ }^{12}{ }^{13}$ We recruited 400 patients, 100 in each group, with atopic asthma, intrinsic (non-atopic) asthma, atopic rhinitis, and atopic eczema from Kawai Clinic, Wakayama Red Cross Medical Centre, and Habikino Hospital, respectively. We selected patients with one principal atopic clinical disorder at the time of examination.

For the British study, 150 subjects were randomly recruited from an obstetric outpatient clinic in Oxfordshire. One hundred and fifty subjects with physician diag- nosed atopic asthma were selected from the Oxford Chest Unit; both controls and patients were white.

All the asthmatic subjects had specialist physician diagnosed asthma with (1) recurrent breathlessness and chest tightness requiring continuing treatment, (2) physician documented wheeze, and (3) documented labile airflow obstruction with variability in serial peak expiratory flow rates $>30 \%$. Marked asthma was designated as chronic rather than episodic asthma, needing chronic therapy with steroids. The diagnosis of rhinitis was based on chronic nasal obstruction or congestion, rhinorrhoea, and sneezing, not caused by chronic infection. The diagnosis of atopic eczema was made on the basis of the morphological appearance of active skin disease, the distribution of skin lesions, the clinical course of the disorder, and a family history of atopy. All cases of eczema met the diagnostic criteria of Hanafin and Rajka. ${ }^{14}$ There were no heavy smokers ( $>20$ cigarettes per day) among these subjects.

Specific IgE against 15 airborne antigens was detected by solid phase immunoassay, MAST (Hitachi, Tokyo, Japan), and we used previously described criteria for a positive titre. A high concentration of total serum IgE (Pharmacia CAP system, Uppsala, Sweden) was taken to be greater than the mean +2 SD. ${ }^{13}{ }^{14}$ Atopy, defined as IgE responsiveness, was diagnosed as the presence of a high concentration of total serum IgE, a positive specific IgE titre $(>0.35 \mathrm{kU} / \mathrm{l})$ against one of 15 highly purified aeroallergens, or a combination of these two features. ${ }^{13} 14$

DNA samples were extracted using a commercial kit (IsoQuick, Microprobe Corporation, Garden Grove, USA). cDNA was extracted using commercial kits (Pharmacia, Sweden). To detect variants, cDNA for the Stat6 coding region was amplified with primers 5'GAA GAC AGC AGA GGG GTT GC and 5'CTG TGG GGG TAGT AGA AGA G. ${ }^{15}$ Sequencing was conducted with the big-dye system $(\mathrm{ABI}, \mathrm{UK})$ and images were visualised in the commercialised POP-6 gel using the automated sequencer (ABI Prism 310 Genetic Analyser). Primers were 5'TGT CTC TGC CCC TGG TGG TC or 5'GGT CCC CAC CTC AGC CAT G. ${ }^{15}$

To conduct the genetic association study, PCR including $1.5 \mathrm{mmol} / 1$ of magnesium chloride and genomic DNA in a $30 \mu \mathrm{l}$ mixture was performed in a Perkin Elmer Cetus thermal cycler. Primers were 5'GGG AAG TTC AGG CTC TGA GAC CC and 5'AGC TCT GTA TGT GTG TGT G. ${ }^{15}$ The underlined sequence was exchanged to incorporate the restriction site. The amplification products were digested with $A c i$.

Contingency table analysis, odds ratios, 95\% confidence intervals, and significance values were estimated by computerised exact methods (SPSS program version 8). Odds ratio (OR) was calculated between high and low risk genotypes and between high and low risk alleles. If the number in the column was less than 10, Fisher's exact test was used. Probability values from this test were corrected for multiple comparisons by multiplying the $p$ value by the number of comparisons that were made (Bonferroni correction).

Mutation scanning enabled us to identify a G2964A variant in a $3^{\prime}$ untranslated region of STAT6. ${ }^{5}$ As shown in tables 1 and 2, the allele frequencies for STAT6 in the two control populations were quite different, $p(G)=0.76$, $\mathrm{p}(\mathrm{A})=0.24$ in the British population and $\mathrm{p}(\mathrm{G})=0.33$ and $\mathrm{p}(\mathrm{A})=0.67$ in the Japanese population $\left(\chi^{2}=82.2, \mathrm{df}=2\right.$, $\mathrm{p}<0.000001)$. There was no significant association between atopic asthma and this STAT6 variant in the British population; no association was seen with any atopy or asthma phenotype. In the Japanese population, mild atopic asthma characterised by positive antigen specific IgE response (ASE) $(<0.75 \mathrm{kU} / \mathrm{l})$ or high total IgE (mean + between $1 \mathrm{SD}$ and $2 \mathrm{SD}$ ) showed a strong association with this variant $(\mathrm{OR}=3.19$ (95\% CI: 1.40-7.08), $\mathrm{p}=0.0043, \mathrm{Pc}=0.016)$. 
Neither adult nor childhood asthma with a marked atopy phenotype (ASE>3.5 kU/1 and total IgE $>$ mean $+2 \mathrm{SD}$ ) was associated with this variant of STAT6. Again, no atopy phenotypes were associated with this variant.

Recent genetic and functional studies highlight the importance of variants of IL- $4 \mathrm{R} \alpha$ in the development of atopy; Ile50 upregulates cellular IgE synthesis and is associated with atopic asthma in a Japanese population, ${ }^{45}$ while Pro478 alters the binding affinity of IRS-1/2, and is associated with lower IgE levels. ${ }^{7}$ No association was found between atopic asthma and these variants in a British population. ${ }^{5}$ These findings emphasise the genetic heterogeneity of atopic disorders, even within one locus in different ethnic groups; they raise the question of interaction between variants of different components of the IL-4/IL-13 signalling pathway. BCL6 might repress stat6 activated transcription ${ }^{16}$ and a variant of BCL6 has been associated with marked atopy. ${ }^{18}$ Interactions among signal transduction molecules of IL-4R $\alpha$ might explain the complex relationships between genetic variants and phenotypes in atopy and asthma. ${ }^{1-3}$

The gene encoding human STAT6, spanning $19 \mathrm{~kb}$ on 12q13-14, consists of 23 exons. ${ }^{19}$ Genome wide searches for atopic asthma showed a strong linkage to $12 \mathrm{q} 14-24 .^{20-22}$ Our present data, showing association between variants of STAT6 and asthma with mild atopy, support the candidacy of STAT6 as an "asthma" locus on $12 \mathrm{q}$ in a Japanese population. Also, the marked difference in genotype frequencies between the British and Japanese populations may explain the "genetic heterogeneity" among and within ethnic groups. ${ }^{1-3}$ Since G2964A variant is located in 3'UTR of the gene, the functional role of this variant remains unknown; it may be in linkage disequilibrium with so far unidentified but functional variants in the regulating or coding parts of STAT6 or variants of the immediately adjacent genes. Further studies are needed to clarify the role of the STAT6 variants in predisposing to asthma among different ethnic groups.

This work was supported in part by a research grant from Mitsubishi Chemical Co (Tokyo, Japan), Ombas Co (Tokyo, Japan), and Glaxo-Wellcome (London, UK). P-SG is a Glaxo-Wellcome scholarship student.

$\mathrm{P}-\mathrm{S} \mathrm{GAO}^{\star}$ $\mathrm{X}-\mathrm{Q} \mathrm{MAO}^{\star}$

M H ROBERTS*

Y ARINOBU†

M AKAIWA $†$

T ENOMOTO

Y DAKE $\ddagger$

M KAWAIS

S SASAKI

N HAMASAKI $†$

K IZUHARA +

T SHIRAKAWA ${ }^{\star}+\dagger$

J M HOPKIN ${ }^{\star}$
*Experimental Medicine Unit, University of Wales Swansea, Singleton Park, Swansea SA2 8PP, UK

†Department of Clinical and Molecular Medicine, Kyushu University Graduate School of Medical Science, Fukuoka, Fapan

$\ddagger$ Department of Otolaryngology, fapanese Red Cross Society, Wakayama Medical Centre, Wakayama, fapan

\Kyoto Preventive Medical Centre, Kyoto, Fapan

ๆDepartment of Paediatrics, Osaka Medical College, Takatsuki, Fapan

t+ Department of Health Promotion and Human Behavior, Kyoto

University Graduate School of Public Health, Kyoto, Fapan

1 Izuhara K, Shirakawa T: Signal transduction via the interleukin-4 receptor and its correlation with atopy. Int $\mathcal{F}$ Mol Genet 1999;3:3-10.

2 Shirakawa T, Deichmann KA, Izuhara K, Mao XQ, Adra CN, Hopkin JM. Atopy, asthma and genetic variants of IL-4 and IL-13 signalling. Immunol Today 2000;21:60-4.

3 Izuhara K, Shirakawa T, Adra CN, Hamasaki N, Hopkin JM. IL-4R $\alpha$ and stat6. Emer Ther Targets 1999;3:381-9.

4 Mitsuyasu H, Izuhara K, Mao XQ, et al. Ile50Val variant of IL-4R $\alpha$ upregulates IgE synthesis and associates with atopic asthma. Nat Genet 1998;19:119-20.

5 Mitsuyasu H, Yanagihara Y, Mao XQ, et al. Dominant effect of Ile50Val variant of the human interleukin-4 receptor $\alpha$ chain in IgE synthesis. $\mathcal{f}$ Immunol 1999;162:1227-31.

6 Hershey GKK, Friedrich MF, Esswein LA, Thomas ML, Chatila TA. The association of atopy with $\alpha$ gain-of-function mutation in the $\alpha$ subunit of the interleukin-4 receptor. N Engl f Med 1997;337:1720-5.

7 Kruse S, Japha T, Tedner M, et al. The polymorphisms S503P and Q576R in the interleukin- 4 receptor $\alpha$ gene are associated with atopy and influence the signal transduction. Immunology 1999;96:365-71.

8 Wang HY, Shelburne CP, Zamorano J, Kelly AE, Ryan JJ, Keegan AD. Effects of an allergy-associated mutation in the human IL-4R $\alpha$ (Q576R) on human IL-4-induced signal transduction. F Immunol 1999;162:4385-9.

9 Takeda K, Kishimoto T, Akira S. Stat6: its role in interleukin 4-mediated biological functions. $\mathcal{F}$ Mol Med 1997;75:317-26.

10 Takeda K, Tanaka T, Shi W, et al. Essential role of Stat6 in IL-4 signalling. Nature 1996;380:627-30

11 Shimada K, van Deursen J, Sangster MY, et al. Lack of IL-4-induced Th2 response and IgE class switching in mice with disrupted Stat6 gene. Nature 1996;380:630-3.

12 Mao XQ, Shirakawa T, Yoshikawa T, et al. Association between mast cell chymase gene and eczema. Lancet 1996;348:581-3.

13 Gao PS, Mao XQ, Kawai M, et al. Negative association between asthma and variants of CC16 (CC10) on chromosome 11q13 in British and Japanese populations. Hum Genet 1998;103:57-9.

14 Hanifin JM, Rajka G. Diagnostic features of atopic dermatitis. Acta Dermatol Venereol 1980;92(suppl):44-7.

15 Hou Z, Schindler U, Henzel WJ, et al. Interleukin-4-induced transcription factor: IL-4 Stat. Science 1994;265:1701-6.

16 Dent AL, Shaffer AL, Yu X, Allman D, Staudt LM. Control of inflammation, cytokine expression, and germline center formation by inflammation, cytokine expression,

$17 \mathrm{Ye} \mathrm{BH}$, Lista F, Coco FL, et al. Alteration of a zinc finger-encoding gene, BCL-6, in diffuse large-cell lymphoma. Science 1993;262:747-50.

18 Adra CN, Gao PS, Mao XQ, et al. Variants of B cell lymphoma 6 (BCL^) and marked atopy. Clin Genet 1998;54:362-4.

19 Patel B, Keck CL, O'Leary RS, Popescu N, LaRochelle WJ. Localisation of the human stat6 gene to chromosome 12q13.3-q14.1, a region implicated in multiple solid tumors. Genomics 1998;52:192-200.

20 CSGA. A genome-wide search for asthma susceptibility loci in ethnically diverse populations. Nat Genet 1997;15:389-92.

21 Ober C, Cox NJ, di Rienzo A, et al. Genome-wide search for asthma susceptibility loci in a founder population. Hum Mol Genet 1998;7:1393-8

22 Wjst M, Fisher G, Immervoll T, et al. A genome-wide search for linkage to asthma. Genomics 1999;58:1-8.

\section{No linkage or association of the IL-4Ra gene Q576R mutation with atopic asthma in Italian families}

EDITOR-Atopy, a familial clinical syndrome of asthma, rhinitis, and eczema, is characterised by $\operatorname{IgE}$ mediated allergy, which results from genetic and environmental events. The disease is immunologically defined by the presence of specific IgE antibodies to common allergens and raised total serum IgE concentrations. Also, because of its high prevalence, age dependent penetrance, and assumed heterogeneity, the mode of inheritance is unknown. ${ }^{1}$ Several genes which affect IgE responsiveness have been reported. ${ }^{2}$
Among the genes that have been reported to affect the atopic phenotype, that for IL4 regulates the production of IgE. ${ }^{34}$ Through its receptor (IL4-R), IL4 signals target cells and tissues to mount a response. The IL4-R $\alpha$ chain binds IL4 and mediates its effect through kinases attached to the intracellular domain. ${ }^{5}$ The IL4-Ra coding gene has been localised to the short arm of chromosome 16 (16p12.1). ${ }^{6}$ Sharing of maternal markers flanking the IL4-Ra gene was recently found in atopy. ${ }^{7}$ A gain of function mutation in the IL4-Ra gene was recently described, and it was reported to be associated with higher levels of expression of CD23 by IL-4, severe atopic dermatitis, raised serum IgE level, or a specific response to a common allergen in a case-control study with 20 affected and 30 unaffected adults in the North American population. ${ }^{8}$ This association study needs confirmation in a different sample. 
In the present study we have investigated the frequency of the IL4-Ra Q576R mutation in a large sample of Italian atopic asthmatic families to determine its involvement in genetic susceptibility to some atopic asthma related phenotypes.

A panel of 851 subjects was analysed, recruited from 192 families with one or more affected children, of whom 133 were attending the Allergy and Pulmonology Clinic of the Department of Paediatrics of the University of Verona, as described previously, ${ }^{9}$ and 59 families attending the Institute of Paediatrics of the Hospital in Bolzano, both located in north east Italy. All the subjects were tested for clinical history, total serum IgE level, skin prick test (SPT), and bronchial hyper-responsiveness (BHR). Clinical asthma was defined according to the American Thoracic Society criteria,${ }^{10}$ including the response to a respiratory questionnaire. BHR to methacholine was defined as PC $20<25$ $\mathrm{mg} / \mathrm{ml}$. Atopy was defined by the presence of one or both of the following criteria: (1) positive SPT to one or more common aeroallergens, such as house dust mites, cat, dog, Alternaria, grass pollen, Parietaria; (2) raised circulating total IgE (from 0 to 10 years of age: age adjusted standard curve, levels above the 90th centile; after 10 years of age: $200 \mathrm{kU} / \mathrm{l}$ ). Among the families, 522 atopic subjects, 477 with a positive SPT, 288 with raised total serum IgE levels, 298 with clinical asthma, and 281 with BHR were analysed. The total is greater than the total number of people, as two or more phenotypes could occur together in the same person.

Genomic DNA was extracted from whole blood, according to standard protocols. To achieve an easy and rapid evaluation of the guanine for adenine substitution at nucleotide 1902 of the IL4-Ra gene, a new protocol based on RG-PCR and nuclease digestion ${ }^{11}$ was developed. This method is faster than the single strand conformation polymorphism technique (SSCP) and DNA sequencing analysis previously described. ${ }^{8} \mathrm{~A}$ mutant oligonucleotide which inserted in the product of DNA amplification a new restriction site for $D d e I$ was synthesised. The primers used were a novel 21-mer forward oligonucleotide (5'TCGGCCCCCACCAGTGGCTCT-3') with an A1899C substitution, and the same reverse oligonucleotide previously described. ${ }^{8}$ The PCR product is a $298 \mathrm{bp}$ fragment. Restriction analysis with DdeI results in two fragments of 277 and $21 \mathrm{bp}$ for the Q576 allele, and a single fragment of $298 \mathrm{bp}$ for the $576 \mathrm{R}$ allele, as shown in fig 1 . All the subjects were genotyped. The data were analysed using the affected sib pairs method implemented in SIBPAL (SAGE package) and the transmission disequilibrium test. ${ }^{14}$ The frequency of the 576R mutation calculated in the family founders was $18 \%(\mathrm{PIC}=0.25)$. In the normal controls, the allele $\mathrm{R}$ frequency was $17.5 \%$ (18/104 alleles). This frequency is similar to that reported for US controls $(10 \%) .^{8}$

Linkage analysis indicated no significant increase in allele sharing for atopy, SPT, IgE, BHR, or asthma, respectively. No allele transmission disequilibrium was observed. Association studies were performed with 52 adult unrelated controls in whom positivity for each of the phenotypes was excluded. Cases were collected from family founder members according to the phenotype (asthmatic: 45, BHR: 60, IgE: 71, SPT: 153, atopy: 175). The case-control analysis did not show a variation in the distribution of alleles between cases and controls in the phenotypes investigated. The statistical tests have sufficient power $(80 \%)$ to detect an association with an odds ratio of 3 for IgE, SPT, atopy, and of 5 for asthma and BHR.

As the informativity of Q576R was limited (PIC 0.25), further linkage analyses with additional IL4-Ra polymorphisms ${ }^{13}$ may better define the putative involvement of the gene in hereditary susceptibility to atopic asthma. Wang et $a l^{14}$ have recently noted that mutation
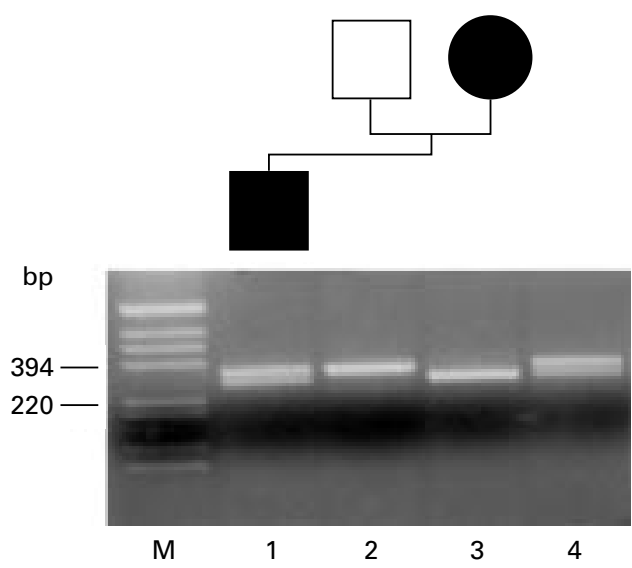

Figure 1 Detection of the IL4-Ra mutation with DdeI restriction analysis of PCR products after modification of the restriction site during PCR. (Top) Pedigree of family BZ78. Filled symbols denote affected family members. (Bottom) Electrophoretic analysis. Lanes 1-3: family members shown above, genotypes are $Q R, R R, Q Q$, respectively; lane 4: $Q R$ control. $M:$ molecular weight marker (1 kb ladder, GIBCO-BRL).

Q576R does not have a direct effect on IL-4 signal transduction in murine cells and suggested that the hypersensitive induction of CD23 in cells derived from human allergy patients may be the result of different or additional alterations in the IL-4 signalling pathway. Another IL4-Ra gene mutation, Ile50Val, was reported to be associated with atopic asthma, increased total IgE, and increased mite specific IgE in a Japanese population, and to upregulate B lymphocyte growth and IgE production in response to IL4 challenge. ${ }^{15}{ }^{16}$ This mutation will now be investigated in the Italian group of patients.

The results reported in this paper were partially obtained by using the program package SAGE, which is supported by a US Public Health Service Resource grant (1 P41 RR03655) from the Division of Research Resources. This work was partially funded by Telethon Italy, Italian Ministry of University and Research, Italian CNR Target Project Biotechnology, and Consorzio Studi Universitari Verona and Italian CNR contribution N.99.02567.CT04 to PFP.

CRISTINA PATUZZO*

ELISABETTA TRABETTI* GIOVANNI MALERBA*

LAURA CARMEN MARTINATI + ATTILIO L BONER†

LYDIA PESCOLLDERUNGG GIOVANNA ZANONIS

PIER FRANCO PIGNATTI*

* Section of Biology and Genetics, DMIBG, University of Verona, Strada

Le Grazie 8, 37134 Verona, Italy

†Section of Paediatrics, DMIBG, University of Verona, Polyclinic " $G B$

Rossi”, Verona, Italy

$¥$ Section of Paediatrics, Hospital of Bolzano, Italy

§Section of Immunology, Department of Pathology, University of Verona, Italy

1 Morton NE. Major loci for atopy? Clin Exp Allergy 1992;22:1041-3.

2 Holgate ST. Asthma genetics: waiting to exhale. Nat Genet 1997;15:227-9.

3 Walley AJ, Cookson WOCM. Investigation of an interleukin-4 promoter polymorphism for associations with asthma and atopy. $₹$ Med Genet 1996; 33:689-92.

4 Rosenwasser LJ. Interleukin-4 and the genetics of atopy. $N$ Engl $\mathcal{F ~ M e d}$ 1997;337:1766-7.

5 Idzerda RL, March CJ, Mosley B, et al. Human interleukin 4 receptor confers biological responsiveness and defines a novel receptor superfamily. Exp Med 1990;171:861-73.

6 Pritchard MA, Baker E, Whitemore SA, et al. The interleukin-4 receptor gene (IL4R) maps to $16 \mathrm{p} 11.2-16 \mathrm{p} 12.1$ in human and to the distal region of mouse chromosome 7. Genomics 1991;10:801-6.

7 Deichmann KA, Heinzmann A, Forster J, et al. Linkage and allelic association of atopy and markers flanking the IL4-receptor gene. Clin Exp Allergy 1998;28:151-5.

8 Hershey GKK, Friedrich MF, Esswein LA, Thomas ML, Chatila TA. The association of atopy with a gain-of-function mutation in the alpha subunit of the interleukin-4 receptor. $N$ Engl f Med 1997;337:1720-5.

9 Trabetti E, Cusin V, Malerba G, et al. Association of the FceRIb gene with bronchial hyperresponsiveness in an Italian population. F Med Genet 1998; 35:680-1.

10 American Thoracic Society. Standards for the diagnosis and care of patients with chronic obstructive pulmonary disease (COPD) and asthma. Am Rev Respir Dis 1988;136:225-44. 
11 Gasparini P, Bonizzato A, Dognini M, Pignatti PF. Restriction site generating-polymerase chain reaction (RG-PCR) for the site generating-polymerase chain reaction (RG-PCR) for the study of some common cystic fibrosis mutations. Mol Cell Probes study of som

12 Schaid DJ. General score tests for associations of genetic markers with disease using cases and their parents. Genet Epidemiol 1996;13:423-49.

13 Deichmann K, Bardutzky J, Forster J, Heinzmann A, Kuehr J. Common polymorphisms in the coding part of the IL4-receptor gene. Biochem Biophys Res Commun 1997;231:696-7.
14 Wang HY, Shelburne CP, Zamorano J, Kelly AE, Ryan JJ, Keegan AD. Cutting edge: effects of an allergy-associated mutation in the human IL-4Ralpha (Q576R) on hur

15 Mitsuyasu H, Izuhara K, Mao XQ, et al. Ile50Val variant of IL4R alpha upregulates IgE synthesis and associates with atopic asthma. Nat Genet 1998;19:119-20.

16 Mitsuyasu $\mathrm{H}$, Yanagihara Y, Mao XQ, et al. Cutting edge: dominant effect of Ile50Val variant of the human IL-4 receptor alpha-chain in IgE synthesis. $\mathcal{F}$ Immunol 1999;162:1227-31.

\section{Importance of the autosomal recessive retinitis pigmentosa locus on 1q31-q32.1 (RP12) and mutation analysis of the candidate gene RGS16 (RGS-r)}

EdITOR-Retinitis pigmentosa (RP, MIM 268000) is the term applied to a clinically and genetically heterogeneous group of retinal degenerations primarily affecting the rod photoreceptors. RP is characterised by progressive loss of vision, initially manifesting as night blindness and reduction in the peripheral visual field, and later involving loss of central vision. ${ }^{1}$ Ophthalmoscopic examination typically shows pigmentary disturbances of the mid-peripheral retina. RP may be inherited as an autosomal recessive, autosomal dominant, digenic, or X linked trait. Autosomal recessive RP (ARRP) accounts for around $20 \%$ of all cases of RP, while sporadic RP, which is presumed to be recessive in most cases, accounts for a further $50 \%{ }^{2}$

Mutations causing autosomal recessive RP (ARRP) have been found in the genes encoding rhodopsin, ${ }^{3}$ the $\alpha$ and $\beta$ subunits of rod phosphodiesterase, ${ }^{45}$ the $\alpha$ subunit of the cyclic GMP gated channel protein, ${ }^{6}$ and the genes RPE65, ${ }^{78}$ RLBP $1,{ }^{9} A B C R,{ }^{10}$ and TULP $1 .{ }^{11}{ }^{12}$ In addition, genetic linkage studies have identified ARRP loci at 1q31-q32.1, ${ }^{13} 14$ 2q31-q33, ${ }^{15}$ 6cen-q15, ${ }^{16}$ and 16p12.1-p12.3. ${ }^{17}$ (MIM numbers for the loci identified by these studies are 180380, 180071, 180072, 123825, $180069,180090,601708,600132,600105$, and 602594 respectively. No MIM number has yet been assigned to the 2q31-q33 and 6cen-q15 loci.) Of these four loci, only linkage to the 1q31-q32.1 locus (RP12) and the 6cen-q15 locus has been reported in more than one pedigree.

The first report of linkage of ARRP to 1q31-q32.1 was in a large inbred Dutch family with ARRP in which most patients exhibited para-arteriolar preservation of the retinal pigment epithelium (PPRPE).$^{13}$ This was followed by linkage of a second, consanguineous, pedigree from Pakistan. ${ }^{14}$ In both the Dutch and the Pakistani families there was evidence that only the branches of the family with PPRPE were linked to 1q31-q32.1, while other branches of each family had classical RP and were unlinked to 1q. In both cases the authors attributed this finding to non-allelic heterogeneity. The occurrence of two very similar eye conditions in one family would presumably be because of the high prevalence of recessive disorders in inbred populations. Recently the critical interval for the RP12 locus was reduced to a $3 \mathrm{cM}$ region between the markers D1S412 and AFM207wb12. ${ }^{18}$

The human gene for a retinally expressed regulator of $G$ protein signalling ( $R G S 16 / R G S-r$ ) has been mapped to 1q25-1q31. ${ }^{19}$ Since it has been shown that RGS16/RGS-r can interact with the $\alpha$ subunit of transducin, a heterotrimeric $G$ protein that is an integral part of the rod phototransduction cascade, the RGS16/RGS-r gene is an excellent functional candidate for ARRP. ${ }^{20}{ }^{21}$ We sought to determine: (1) how important the 1q31-q32.1 locus is as a cause of ARRP by performing linkage analysis and homozygosity mapping in a panel of ARRP families from Europe and Asia, and (2) whether mutations in RGS16/ $R G S-r$ are responsible for ARRP at this locus (RP12). In order to perform linkage analysis and homozygosity mapping, 14 large/consanguineous families with ARRP from the UK (two families), Pakistan (nine families), and Spain (three families) were ascertained. In addition, PMK214, the family originally studied by Leutelt $e t a l,{ }^{14}$ was included for mutation screening of the candidate gene RGS16/RGS-r. Clinical examination of all affected subjects showed typical features of retinitis pigmentosa (pigmentary retinopathy, associated with symptoms of night blindness and loss of visual fields). Informed consent was obtained by local clinicians.

To identify the locus responsible for the disease in each family we performed a linkage or homozygosity analysis. The initial set of markers chosen to be analysed were those corresponding to the loci of genes responsible for ARRP, and those known to flank the ARRP loci for which no gene has as yet been identified (table 1). When evidence of linkage was obtained for the 1q31-q32.1 locus, further polymorphic markers from this region were analysed to determine whether recombinant subjects within the family would permit further refinement of the locus. Marker order was determined from the Généthon sex averaged genetic map. ${ }^{22}$ Primers were obtained from the MapPairs set (Research Genetics, Huntsville, AL), or synthesised commercially according to data from GDB (Johns Hopkins University: http://gdbwww.gdb.org/).

Non-radioactive PCR was performed with $300 \mathrm{ng}$ of genomic DNA, 10 pmol of each primer, $200 \mu \mathrm{mol} / 1$ dNTPs, $1.5 \mathrm{mmol} / 1 \mathrm{MgCl}_{2}$, and 1 unit of Taq DNA polymerase. A three stage PCR consisting of 35 cycles of $94^{\circ} \mathrm{C}, 50-62^{\circ} \mathrm{C}$, and $72^{\circ} \mathrm{C}$, each for one minute, was used. The amplified products were then separated by electrophoresis on $6-8 \%$ non-denaturing polyacrylamide gels (Protogel, National Diagnostics) and stained with ethidium bromide. Two point lod scores were calculated using the LINKAGE package. ${ }^{23}$

Primers for heteroduplex analysis and direct sequencing of the five exons and the intron-exon boundaries of the $R G S 16 / R G S-r$ gene were designed using the published

Table 1 Known loci for ARRP including some of the polymorphic markers used in this study

\begin{tabular}{llll}
\hline Locus & Gene & Reference & Markers used \\
\hline 1p31 & RPE65 & 7 & D1S1665, D1S1669 \\
1p13-21 & ABCR & 10 & D1S236, D1S2813 \\
1q31-q32.1 & RP12 & 13,14 & F13B, D1S2622 \\
2q31-q33 & & 15 & D2S152, D2S157 \\
3q21-q24 & Rhodopsin & 3 & D3S1292, D3S1589 \\
4p16.3 & PDEB & 6 & PDEB intragenic, D4S412 \\
4p14-q13 & CNGC & 5 & D4S189, D4S405 \\
5q31.2-q34 & PDEA & 4 & D5S536, D5S412 \\
6p21 & TULP1 & 11,12 & D6S291, D6S276 \\
15q26 & RLBP1 & 9 & D15S127, D15S124 \\
16p12.1-p12.3 & & 17 & D16S287, D16S292 \\
\hline
\end{tabular}




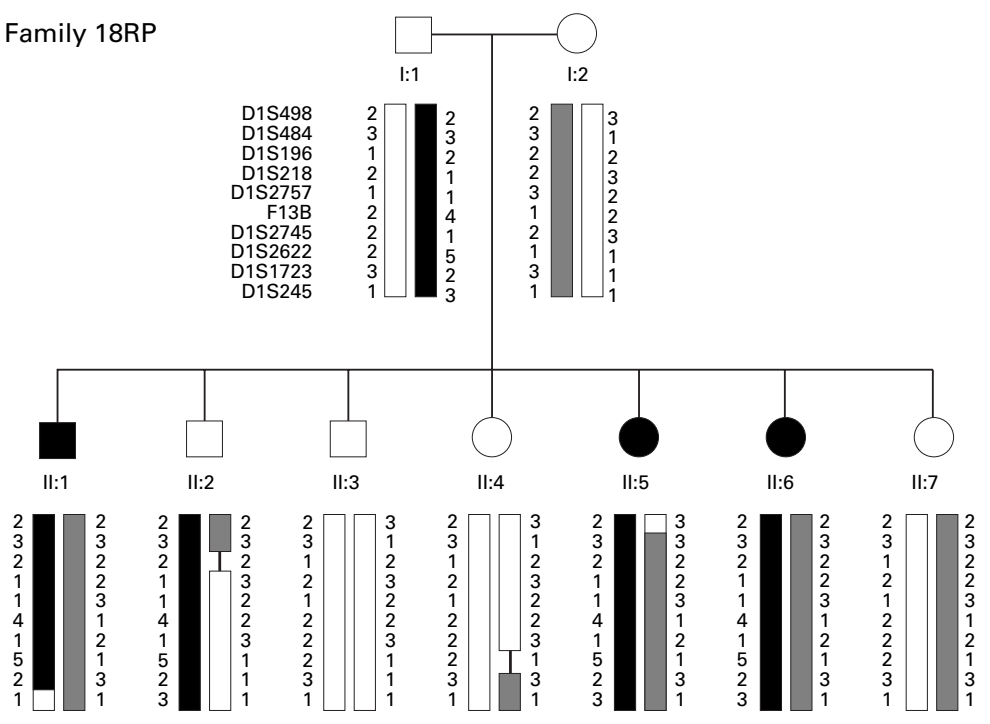

Family RP112

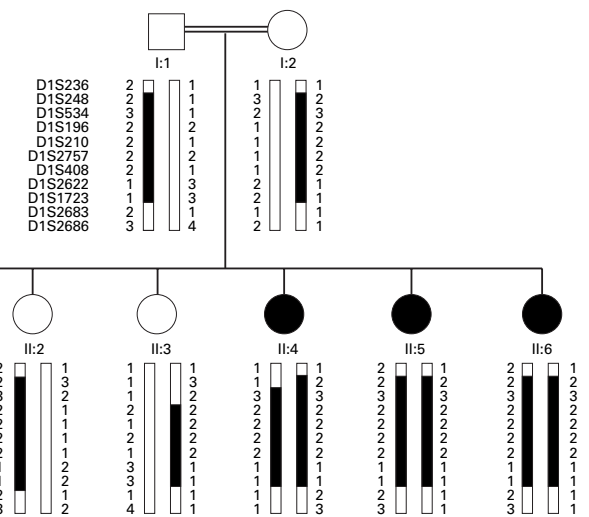

Family RP23/91

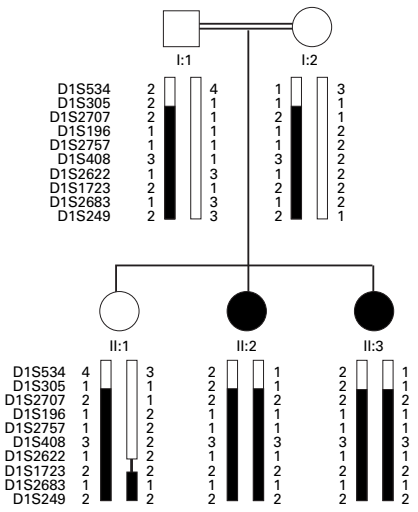

Figure 1 Pedigrees of families exhibiting evidence of linkage to 1q31-q32.1 showing haplotypes for polymorphic markers in this region. Maximum lod scores for each family were: $18 R P \mathrm{Zmax}=1.70$ (at $\theta=0.00$ ) for the marker $\mathrm{F} 13 \mathrm{~B}, \mathrm{RP} 112 \mathrm{Zmax}=2.48$ at D1S2622, and RP23/91 Zmax=1.63 at D1S408. The RP12 locus lies between markers D1S2757 and D1S2622. Black or hatched bars situated between the marker alleles indicate the affected haplotype.

genomic sequence ${ }^{19}$ (Genbank AF009356) as follows: exon $1 \mathrm{~F}$ - GCCTGCCACCATCCTGCCTAC; 1R - CTCTCT CTCAAGCCTCTAGC (208 bp); exon 2F - CACCAC CCAGAGCTCTTCTGG; 2R - GTTGCCAAGGTCCA CTTAGCG (312 bp); exon3F - CAGCAATCACCAAGCAAGCC; 3R - CAGGCTCTCAGCAGTCCTGG (281 bp); exon 4F - GATCCCCTAGTGTGCCAGCCTC; 4R CTCTACACCTAGCCCTTCCTCC; (429 bp); exon 5F CACTTCCTGATGCAGCATCCG; 5R CTCTTCCCG GCTGGCTTCC (372 bp). Polymerase chain reaction PCR was performed in a $50 \mu$ reaction with $1 \mu \mathrm{g}$ of genomic DNA, 20 pmol of each primer, $200 \mu \mathrm{mol} / 1$ dNTPs, $0.75-1.5 \mathrm{mmol} / 1 \mathrm{MgCl}_{2}$, and 1 unit of Taq DNA polymerase. A three stage PCR consisting of 40 cycles of $94^{\circ} \mathrm{C}, 55-60^{\circ} \mathrm{C}$, and $72^{\circ} \mathrm{C}$, each for one minute, was used. The resulting product was allowed to cool slowly to room temperature to maximise the formation of heteroduplexes. ${ }^{24}$

All five exons of $R G S 16 / R G S-r$ were directly sequenced in two or more members of each potentially $1 \mathrm{q}$ linked family using an automated sequencer (ABI Biosystems model 373). PCR products were purified and then reamplified using the FS kit (Perkin Elmer). Variants were sequenced in both the forward and reverse directions to confirm the location of sequence changes.

$A c i$ restriction digests were performed directly on $20 \mu \mathrm{l}$ of exon 4 PCR product by overnight incubation at $37^{\circ} \mathrm{C}$. The resultant bands were photographed after electrophoresis on a $2 \%$ agarose gel and stained with ethidium bromide.

Three of the 14 families studied showed evidence of linkage to the 1q31-q32.1 ARRP locus and were excluded by linkage analysis from all of the other ARRP loci (fig 1). Two of these pedigrees were of Pakistani origin (18RP and RP112) and one was Spanish (RP23/91). Analysis of additional polymorphic markers on $1 \mathrm{q}$ in these families did not permit further refinement of the RP12 locus.

Clinical examination of the small Spanish RP23/91 family showed para-arteriolar preservation of the retinal pigment epithelium (PPRPE) as previously described in RP12 linked families. ${ }^{13} 14$ A relative lack of pigmentation adjacent to retinal arterioles was also seen in the Pakistani RP112 family. This feature could not be conclusively shown in the 18RP pedigree, possibly because the three affected subjects are only 22, 14, and 13 years old respectively. The fundus photograph showing PPRPE in the 
Table 2 Comparison of the disease haplotypes in the three families of Pakistani origin for polymorphic markers in the critical region on 1q31

\begin{tabular}{lllll}
\hline \multirow{2}{*}{ Marker } & \multirow{2}{*}{$\begin{array}{l}\text { RP112 } \\
\text { Consanguineous }\end{array}$} & Paternal & Maternal & $\begin{array}{l}\text { PMK214 } \\
\text { Consanguineous }\end{array}$ \\
\cline { 3 - 4 } & & 3 & 3 & 2 \\
D1S2877 & 1 & 1 & 3 & 4 \\
D1S2757 & 3 & 4 & 1 & 1 \\
F13B & 1 & 1 & 2 & 2 \\
D1S2745 & 3 & 1 & 3 & 3 \\
D1S1660 & 2 & 5 & 1 & 3 \\
D1S2622 & 2 & 2 & 4 & 1 \\
D1S1723 & 3 & & &
\end{tabular}

original paper of van Soest et $a l^{13}$ shows heavy retinal pigmentation and was taken from a 41 year old patient.

In order to show that the three families of Pakistani origin were not distantly related and that RP12 is an important ARRP locus in that population, we compared the disease haplotypes for markers within and immediately surrounding the RP12 locus in each family (table 2). The maternal disease haplotype in family $18 \mathrm{RP}$ and the homozygous disease haplotype for PMK214 was identical for three adjacent markers (F13B, D1S2745, and D1S1660) within the RP12 locus. A founder effect could not be excluded in these two families. However, the paternal disease haplotype in 18RP and that seen in RP112 were entirely different, indicating that at least three different RP12 alleles may exist in these families.

These four families then underwent mutation screening of the five exons of the RGS16/RGS-r gene by heteroduplex analysis and direct sequencing. Heteroduplexes were observed with the exon 4 product in the parents from consanguineous families RP112, PMK214, and RP23/91, but not in their affected children. No heteroduplexes were observed in members of $18 \mathrm{RP}$.

Direct sequencing of the exon 4 and exon 5 products showed polymorphisms in introns 3 ( -10 a to g) and 4 $(-35 \mathrm{c}$ to $\mathrm{t})$ respectively. The intron $3 \mathrm{a}>\mathrm{g}$ change, which creates a recognition site for the restriction enzyme $A c i \mathrm{I}$, was found to be present in the heterozygous state in the parents from families RP112, PMK214, and RP23/91 in whom a heteroduplex band had been observed, and in the homozygous state in their affected children. AciI restriction digest analysis was, therefore, used to show the segregation of this polymorphism in the large linked family PMK214. All seven affected members of this consanguineous pedigree were found to be homozygous for the intron 3 $(-10$ a to $\mathrm{g})$ polymorphism. This indicates that RGS16/ $R G S-r$ cannot be excluded from the critical genetic interval for RP12 in this family. In addition, 10 Pakistani controls were subjected to $A c i$ I restriction digest analysis, two of whom were found to be heterozygous for the intron 3 polymorphism. No sequence variants within the coding regions of $R G S 16 / R G S-r$ were observed in any subject.

While there are nine published loci for autosomal dominant RP (ADRP), rhodopsin mutations may account for up to $25 \%$ of cases. ${ }^{25}$ In contrast, none of the 11 published genes/loci for ARRP has been estimated to account for more than $5 \%$ of recessive RP. In this study, two out of nine Pakistani and one out of five European families showed evidence of linkage to RP12 and exclusion from the other loci. While this result is based upon a small sample it suggests that mutations in the gene situated at this locus may be responsible for a significant proportion of ARRP, at least in the Pakistani population.

In rod photoreceptors, the GTP bound $\alpha$ subunit of the heterotrimeric $G$ protein transducin $(T \alpha)$ activates the effector enzyme, cGMP phosphodiesterase (PDE), by binding to its inhibitory gamma subunit (PDE $\gamma$ ). Hydrolysis of GTP by the intrinsic GTPase activity of T $\alpha$ releases bound $\mathrm{PDE} \gamma$ and results in inactivation of PDE $\alpha \beta$ during the phase of recovery from photoactivation. In vitro experiments with purified $\mathrm{T} \alpha$ subunits have shown that the intrinsic GTPase activity of $\mathrm{T} \alpha$ is inadequate to account for the rapid hydrolysis of GTP that is observed in vivo. ${ }^{26}$ It has been postulated, therefore, that a GTPase activating protein (GAP) that is capable of greatly accelerating this process must exist in rod outer segments.

RGS16/RGS-r, which is highly expressed in the retina, has been proposed to fill the role of the T $\alpha$ GAP. ${ }^{19}$ It has been shown in vitro that the rate of transducin GTPase activity in the presence of RGS16/RGS-r is sufficient to correlate with the in vivo recovery kinetics of the visual cascade, and that in addition RGS16/RGS-r facilitates signal termination by competing with and thereby displacing PDE $\gamma$ from $T \alpha .{ }^{20}{ }^{21}$ This biochemical evidence suggests an important role for RGS16/RGS-r in retinal photoreceptors.

Since the human gene for RGS16/RGS-r has been mapped to $1 \mathrm{q} 25-1 \mathrm{q} 31,{ }^{19}$ and since in the present study it could not be excluded from the RP12 locus by analysis of the intron 3 polymorphism in the linked family PMK214, this gene must remain as a potential candidate for the ARRP linked to this locus. We failed to find any sequence changes in the coding region of the gene in our four families, though it is possible that disease causing mutations may lie in the promoter region of the gene, which was not screened.

This study must, however, reduce the prospect of $R G S 16 / R G S-r$ mutations being found in other 1q linked families and lead to a renewed search for candidates within the RP12 critical interval.

We would like to thank the family members for taking part in this study. Drs David A R Bessant and Annette M Payne are supported by the Medical Research Council of the UK (grant No G9301094). We would also like to thank the Wellcome Trust for an Equipment Grant for the sequencing facility (No 039283/2/93/Z/MW/JF).

DAVID A R BESSANT ${ }^{\star}+$ ANNETTE M PAYNE* BRYAN E SNOW GUILLERMO ANTIÑOLOS S QASIM MEHDI ALAN C BIRD $†$ DAVID P SIDEROVSKI

${ }^{*}$ Department of Molecular Genetics, Institute of Ophthalmology, TACHARYA*

University College London, London EC1V 9EL, UK

tMoorfields Eye Hospital, London, UK

$\ddagger$ Quantitative Biology Laboratory, Amgen Institute, Toronto, Ontario,

Canada

ऽUnidad de Genética Médica y Diagnóstico Prenatal, Hospital Maternal, Hospital Universitario "Virgen del Rocio", Sevilla, Spain

IDr A Q Khan Research Laboratories, Biomedical and Genetic

Engineering Division, Islamabad, Pakistan

1 Bird AC. Retinal photoreceptor dystrophies. Am f Ophthalmol 1995; 119:543-62.

2 Jay M. On the heredity of retinitis pigmentosa. Br f Ophthalmol 1982; 66:405-16

3 Rosenfeld P, Cowley G, McGee T, Sandberg M, Berson E, Dryja T. A null mutation in the rhodopsin gene causes rod photoreceptor dysfunction and mutation in the rhodopsin gene causes rod photoreceptor dysfunction

4 Huang SH, Pittler SJ, Huang X, Oliveira L, Berson EL, Dryja TP. Autosomal recessive retinitis pigmentosa caused by mutations in the $\alpha$ Autosomal recessive retinitis pigmentosa caused by mutations in
subunit of rod cGMP phosphodiesterase. Nat Genet 1995;11:468-71.

5 McLaughlin ME, Ehrhart TL, Berson EL, Dryja TP. Mutation spectrum of McLaughlin ME, Ehrhart TL, Berson EL, Dryja TP. Mutation spectrum of
the gene encoding the $\beta$ subunit of rod phosphodiesterase among patients the gene encoding the $\beta$ subunit of rod phosphodiesterase among patients
with autosomal recessive retinitis pigmentosa. Proc Natl Acad Sci USA with autosomal reces

1995;92:3249-53

6 Dryja TP, Finn TJ, Peng YW, McGee TL, Berson EL, Yau KW. Mutations in the gene encoding the $\alpha$ subunit of rod cGMP-gated channel in autosomal recessive retinitis pigmentosa. Proc Natl Acad Sci USA 1995;92: 10177-81.

7 Gu SM, Thompson DA, Srikumari CRS, et al. Mutations in RPE65 cause autosomal recessive childhood-onset severe retinal dystrophy. Nat Genet 1997;17:194-7.

8 Marlhens F, Bareil C, Griffoin JM, et al. Mutations in RPE65 cause Leber's congenital amaurisis. Nat Genet 1997;17:139-41.

9 Maw MA, Kennedy B, Knight A, et al. Mutations in the gene encoding cellular retinaldehyde-binding protein in autosomal recesssive retinits pigmentosa. Nat Genet 1997;17:198-200.

10 Martinez-Mir A, Paloma E, Allikmets R, et al. Retinitis pigmentosa caused by a homozygous mutation in the Stargardt disease gene ABCR. Nat Genet by a homozygous

11 Banerjee P, Kleyn PW, Knowles JA, et al. 'TULIP1' mutation in two recessive extended Dominican kindreds with autosomal recessive retinitis pigmentosa. Nat Genet 1998;18:177-9. 
12 Hagstrom SA, North MA, Nishina PM, Berson EL, Dryja TP. Recessive mutations in the gene encoding the tubby-like protein TULIP1 in patients mutations in the gene encoding the tubby-like prote
with retinitis pigmentosa. Nat Genet 1998;18:174-6.

13 van Soest S, van den Born LI, Gal A, et al. Assignment of a gene for autosomal recessive retinitis pigmentosa (RP12) to chromosome 1q31-q32.1 in an inbred and genetically heterogeneous disease population. Genomics 1994;22:499-504.

14 Leutelt J, Oehlmann $\mathrm{R}$ Younus $\mathrm{F}$, et al. Autosomal recessive retinitis pigmentosa locus maps on chromosome $1 \mathrm{q}$ in a large consanguineous family from Pakistan. Clin Genet 1995;47:122-4.

15 Bayes M, Goldaracena B, MartinezMir A, et al. A new autosomal recessive retinitis pigmentosa locus maps on chromosome 2q31-q33. f Med Genet 1998;35:141-5.

16 Ruiz A, Borrego S, Marcos I, Antiñolo G. A major locus for autosomal recessive retinitis pigmentosa on $6 \mathrm{q}$, determined by homozygosity mapping of chromosomal regions that contain of chromosomal regions that contain gamm

17 Finckh U, Xu S, Kumaramanickavel G, et al. Homozygosity mapping of autosomal recessive retinitis pigmentosa locus (RP22) on chromosome autosomal recessive retinitis pigmentosa

18 van Soest S, van Rossem MJ, Heckenlively JR, et al. Integrated genetic and physical map of the 1q31-q32.1 region, encompassing the RP12 locus, the F13B and HF1 genes, and the EEF1AL11 and RPL30 pseudogenes. Cytogenet Cell Genet 1999;84:22-7.
19 Snow BE, Antonio L, Suggs S, Siderovski DP. Cloning of a retinally abundant regulator of G-protein signaling (RGS-r/RGS16): genomic structure and chromosomal localization of the human gene. Gene 1998;206:247-53.

20 Natochin M, Granovsky AE, Artemyev NO. Regulation of transducin GTPase activity by human retinal RGS. F Biol Chem 1997;272:17444-9.

21 Wieland T, Chen CK, Simon MI. The retinal specific protein RGS-r competes with the gamma subunit of cGMP phosphodiesterase for the alpha subunit of transducin and facilitates signal termination. F Biol Chem 1997; 272:8853-6.

22 Dib C, Faure S, Fizames C, et al. A comprehensive genetic map of the human genome based on 5,264 microsatellites. Nature 1996;380:152-4.

23 Lathrop GM, Lalouel JM. Easy calculation of lod scores and genetic risks on small computers. Am f Hum Genet 1984;36:460-5.

24 Keen J, Lester D, Inglehearn CF, Curtis A, Bhattacharya SS. Rapid determination of single base pair mismatches as heteroduplexes on Hydrolink gels. Trends Genet 1991;7:5

25 Inglehearn CF, Tarttelin EE, Plant C, et al. A linkage survey of 20 dominant retinitis pigmentosa families: frequencies of the nine known loci and revidence for further heterogeneity. $\mathcal{F}$ Med Genet 1998;35:1-5.

26 Angleson JK, Wensel TG. A GTPase accelerating factor for transducin, distinct from its effector cGMP phosphodiesterase, in rod outer segment membranes. Neuron 1993;11:939-9.
Incidence and molecular mechanism of aberrant splicing owing to a $\mathrm{G} \rightarrow \mathrm{C}$ splice acceptor site mutation causing Smith-Lemli-Opitz syndrome

EdITOR-Smith-Lemli-Opitz (SLO) syndrome (MIM 270400) is an autosomal recessive disorder characterised by a wide spectrum of developmental abnormalities including craniofacial malformations, growth and mental retardation, and multiple congenital anomalies..$^{1-3}$ The disorder is caused by deficient activity of 7-dehydrocholesterol reductase (7-DHCR), the enzyme that catalyses the reduction of the $\mathrm{C}_{7}-\mathrm{C}_{8}(\Delta 7)$ double bond of 7-dehydrocholesterol to produce cholesterol. $^{45}$ As a consequence, patients with SLO syndrome have low plasma cholesterol and raised plasma 7-dehydrocholesterol concentrations, thus constituting the biochemical hallmark used to confirm the clinical diagnosis of the syndrome.

Recently, we and others have identified the cDNA coding for human 7-DHCR and confirmed that SLO syndrome is caused by mutations in the corresponding 7-DHCR gene. ${ }^{6-8}$ So far, 19 different disease causing mutations have been reported, which were identified after analysis of only 33 patient alleles. In our previous report, we described an aberrantly spliced mutant 7-DHCR cDNA with an insertion of $134 \mathrm{bp}$ which we identified in two of three Dutch patients analysed with SLO syndrome, one of whom was a homozygote and the other a compound heterozygote. ${ }^{6}$ Upon translation, this insertion not only introduces additional amino acids but also causes a frameshift, which leads to an inactive, truncated protein with a changed C-terminus. ${ }^{6}$ Since the same insertion was also reported by two other groups, ${ }^{78}$ and since the affected patients were not related to one another, this finding suggested that the insertion is the result of a frequently occurring mutation. To evaluate this, we analysed 17 additional patients with SLO syndrome for the occurrence of the $134 \mathrm{bp}$ insertion using allele specific RT-PCR. Furthermore, we studied the underlying mechanism that gives rise to the aberrant splicing, which results in the 134 bp insertion at the cDNA level.

First strand cDNA was synthesised from total RNA isolated from leucocytes or primary skin fibroblasts ${ }^{9}$ obtained from 17 patients who were diagnosed with SLO syndrome on the basis of clinical features and raised serum levels of 7-dehydrocholesterol. In the patients for whom fibroblasts were available, the biochemical defect was confirmed by the detection of reduced enzyme activity of 7-DHCR using a previously described ergosterol to brassicasterol conversion assay ${ }^{10}$ followed by sterol analysis using gas chromatography-mass spectrometry. ${ }^{11}$ To determine the presence of the $134 \mathrm{bp}$ insertion, the first strand cDNA was used as template for the amplification by PCR of the second half of the coding region of 7-DHCR cDNA using primer set $\mathrm{DHCR}_{684-703}$ and $\mathrm{DHCR}_{1563-1544}$ (table 1). This primer set generates a single fragment of $915 \mathrm{bp}$ in control subjects and patients with SLO syndrome, who do not harbour the $134 \mathrm{bp}$ insertion (fig 1 , lanes 2 and 3). In the previously described patient who was a homozygote for the insertion, ${ }^{6}$ a single fragment of $1049 \mathrm{bp}$ is amplified (fig 1, lane 4 ), while in a patient who is a compound heterozygote for the insertion, both fragments of 915 and $1049 \mathrm{bp}$ are amplified. In compound heterozygotes, an additional intermediate sized fragment is frequently observed, which is a heteroduplex form composed of one strand of both fragments, as could be shown by mixing the 915 and 1049 $\mathrm{bp}$ fragments followed by one cycle of melting and annealing (not shown). Of the 20 patients thus analysed, including the three patients previously reported ${ }^{6}$ and three pairs of sibs, one patient was a homozygote and 13 patients heterozygotes for the insertion. Of these 14 patients, eight patients (including the homozygote and two pairs of sibs) were of Dutch origin, four patients of German origin (including one pair of sibs), one patient of Belgian and one patient of Spanish origin.

In their recent paper, Fitzky et al reported that two of their 13 patients with SLO syndrome were compound heterozygotes for the $134 \mathrm{bp}$ insertion. They also indicated that the insertion was caused by a $\mathrm{G} \rightarrow \mathrm{C}$ transversion in the

Table 1 PCR primers used in this study

\begin{tabular}{|c|c|}
\hline Primer* & Sequence $\left(5^{\prime} \rightarrow 3^{\prime}\right)$ \\
\hline [-21M13] & TGTAAAACGACGGCCAGT \\
\hline $\mathrm{DHCR}_{-58-38}$ & [-21M13]-GGTTCAAGAAGGAAAAGTTCCC \\
\hline $\mathrm{DHCR}_{684-703}$ & [-21M13]-TCGGGAAGTGGTTTGACTTC \\
\hline $\mathrm{DHCR}_{930-949}$ & [-21M13]-CTGTGTCTGGCTGCCTTATC \\
\hline DHCR $_{949-967}$ & [-21M13]-CTTTACACGCTGCAGGGTC \\
\hline DHCR-ins $_{21-39}$ & [-21M13]-CGTGTGTCAGAGGCAGAGC \\
\hline [M13rev] & CAGGAAACAGCTATGACC \\
\hline DHCR $_{979-960}$ & [M13rev]-ACACCAAGTACAGACCCTGC \\
\hline $\mathrm{DHCR}_{996-978}$ & [M13rev]-CAGCTGCACGGGGTGGTAC \\
\hline $\mathrm{DHCR}_{1563-1544}$ & [M13rev]-GGGCTCTCTCCAGTTTACAG \\
\hline DHCR-ins $_{113-95}$ & [M13rev]-GTCAAGCGGTGCTTTGCCC \\
\hline
\end{tabular}

PCR conditions are available on request. ${ }^{\star}$ Numbering of nucleotide residues according to previously published 7 -DHCR cDNA sequence. ${ }^{6}$ 


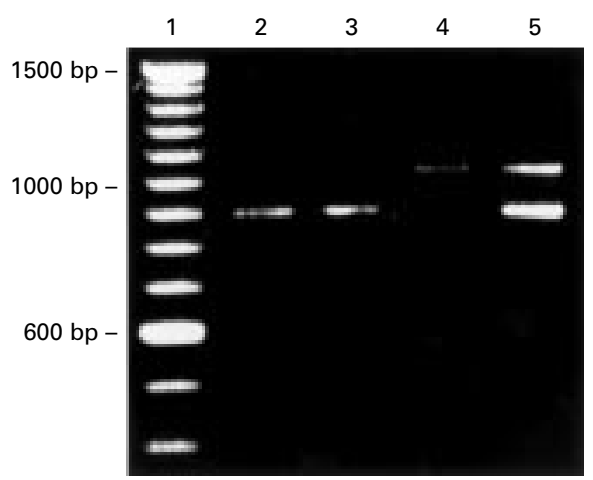

Figure 1 Identification of the 134 bp insertion by RT-PCR. The second half of 7-DHCR cDNA was amplified by RT-PCR from a control subject (lane 2) and three genotypically different patients with SLO syndrome using primer set $D H C R_{684-703}$ and $D H C R_{1563-1544}$ (see table 1). One patient contained two missense mutations (lane 3) while the other two patients were either homozygous (lane 4) or heterozygous for the 134 bp insertion (lane 5). Lane 1 contains a $100 \mathrm{bp}$ DNA molecular weight marker.

splice acceptor site of intron 8 of the 7-DHCR gene, which is included in the $134 \mathrm{bp}$ insertion of the corresponding cDNA, but they did not study the molecular background in further detail. Therefore, we amplified the corresponding DNA region by PCR from genomic DNA isolated from two control subjects and two patients with SLO syndrome to confirm that the insertion is caused by a mutation in a splice acceptor site and to determine the underlying mechanism that causes the specific splicing defect. To this end two separate primer sets were used. The first primer set consisted of a forward primer designed on the cDNA sequence $5^{\prime}$ of the site of insertion $\left(\mathrm{DHCR}_{930-949}\right)$ and a reverse primer designed on the $134 \mathrm{bp}$ insertion sequence (DHCR-ins ${ }_{113-95}$ ), which amplified a genomic DNA fragment of approximately $2 \mathrm{~kb}$. The second set consisted of a forward primer designed on the $134 \mathrm{bp}$ insertion sequence $\left(\mathrm{DHCR}-\right.$ ins $\left._{21-39}\right)$ and a reverse primer designed on the cDNA sequence 3 ' of the site of insertion $\left(\mathrm{DHCR}_{996-978}\right)$, which amplified a genomic DNA fragment of approximately $120 \mathrm{bp}$. Taken together, these results indicated that the $134 \mathrm{bp}$ insertion resulted from a partial retention of the 3 ' end of an intron with an approximate size of $2 \mathrm{~kb}$.
Indeed, sequence analysis of the two overlapping genomic DNA fragments which were amplified from the two control subjects identified consensus sequences for both a splice donor site and a splice acceptor site, which confirmed that the complete intron sequence, which comprises $1965 \mathrm{bp}$, was isolated (fig 2). Sequence analysis of the same overlapping genomic DNA fragments amplified from the two patients with SLO syndrome confirmed that the retention was caused by a $\mathrm{G} \rightarrow \mathrm{C}$ transversion at the -1 position of the splice acceptor site of the intron. This mutation disrupts the consensus sequence of the splice acceptor site and leads to alternative splicing of the transcript at a site located $134 \mathrm{bp} 5^{\prime}$ of the original splice site. The intron DNA sequence adjacent to this alternative site of splicing shows strong homology to the consensus sequence of a splice acceptor site and is preceded by a DNA sequence which has strong homology to the branch point consensus sequence, thus constituting quite a strong alternative splice acceptor site (fig 2).

The (compound) heterozygous presence of the $134 \mathrm{bp}$ insertion enabled allele specific amplification by PCR of the two cDNAs, which could then be directly sequenced to identify the syndrome causing mutations on both alleles. To amplify the cDNA without insertion, primers $\mathrm{DHCR}_{979-}$ 960 and $\mathrm{DHCR}_{949-967}$, which both span the site of insertion (after nucleotide 963), were used in combination with, respectively, a forward primer in the $5^{\prime}\left(\mathrm{DHCR}_{-58-38}\right)$ and a reverse primer in the 3' region $\left(\mathrm{DHCR}_{1563-1544}\right)$. This amplification produced two overlapping fragments of 1073 and $650 \mathrm{bp}$, respectively (fig 3). The cDNA containing the 134 bp insertion was specifically amplified using the same 5' and 3 ' region primers in combination with the DHCRins $_{113-95}$ and DHCR-ins ${ }_{21-39}$ primers designed on the insertion DNA sequence. This amplification produced two overlapping fragments of 1170 and $748 \mathrm{bp}$, respectively (fig 3). Using the latter two primer sets, the cDNAs containing the $134 \mathrm{bp}$ insertion which were identified in the patients with SLO syndrome (see above) were amplified and analysed by sequencing. In all cases, the same $\mathrm{G} \rightarrow \mathrm{C}$ mutation at the -1 position of the splice acceptor site was identified.

To conclude, using allele specific 7-DHCR cDNA amplification, we analysed 20 patients with SLO syndrome and identified one patient as a homozygote and 13 patients, including three pairs of sibs, as heterozygotes for the $G \rightarrow C$

(A)

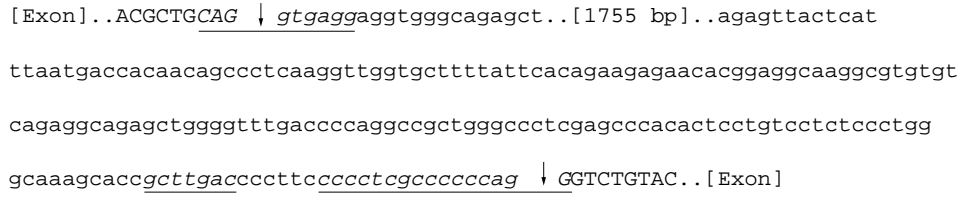

(B)

[Exon]..ACGCTGCAG \gtgaggaggtgggcagagct..[1755 bp]..agagttactcat

ttaatgaccacaacagccctcaaggttggtgcttttattcacag | aagagaacacggaggcaaggcg

tgtgtcagaggcagagctggggtttgaccccaggccgetgggccetcgagcccacactcctgtcctc

tccetgggcaaagcaccgettgaccettcccctcgeccccacGGTCTGTAC . [Exon]

Figure 2 Molecular basis of the 134 bp insertion. (A) Sequence analysis of the genomic DNA region from which the 134 bp insertion originates and amplified by PCR from control subjects identified an intron of $1965 \mathrm{bp}$ (small lettering) with consensus splice donor, branch point, and splice acceptor site sequences (italics and underlined). The complete nucleotide sequence of the intron can be obtained from GenBank under accession number AF132981. (B) In the patients, a $G \rightarrow C$ mutation at the -1 position of the authentic splice acceptor site (double underline) results in alternative splicing at a cryptic splice acceptor site located $134 \mathrm{bp} 5$ ' of the authentic splice acceptor site and preceded by a consensus branch point sequence (italics and underlined). The 134 bp intron sequence, which is retained as a result of the alternative splicing, is indicated in bold. Original exon sequences are indicated in capitals. Consensus sequences are defined as follows: splice donor site, [exon].. (C/A) AG $\downarrow$ gt(a/g)agt.. [intron]; branch point, (t/c)n(t/c)t(g/a) ac (18-40 bp 5' of splice acceptor site); splice acceptor site, [intron].. (t/c) ${ }_{11} n(t / c)$ ag $\downarrow G / A . .[$ exon]. 


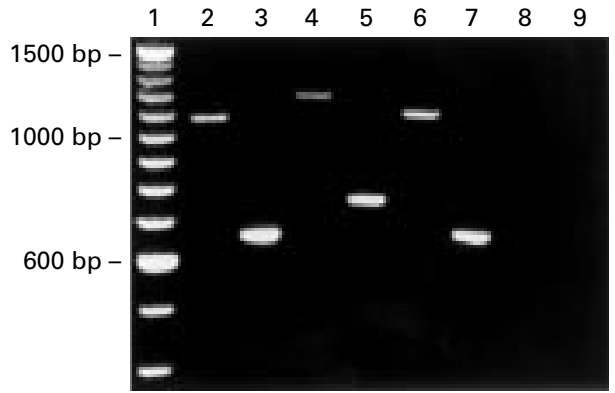

Figure 3 Allele specific amplification of $c D N A$ s with and without the 134 bp insertion. The 7-DHCR cDNA without the 134 bp insertion was specifically amplified in two overlapping fragments from a patient heterozygous for the insertion (lanes 2 and 3) and a patient with two missense mutations (lanes 6 and 7) using primer sets $D H C R_{-58-38}$ and $D H C R_{979-967}$ (lanes 2 and 6), and $\mathrm{DHCR}_{949-967}$ and $\mathrm{DHCR}_{1563-1544}$ (lanes 3 and 7), respectively. The cDNA containing the $134 \mathrm{bp}$ insertion was specifically amplified in two overlapping fragments from the heterozygous patient using primer sets DHCR ${ }_{-58-38}$ and DHCR-ins ${ }_{113-95}$ (lane 4), and DHCR-ins 21-39 $_{\text {and }}$ ${ }_{D H C R_{1563-1544}}$ (lane 5). Using the latter two primer sets, no fragments were amplified from the patient who had two missense mutations and lacked the splice site mutation causing the insertion (lanes 8 and 9).

transversion which results in the partial retention of intron 8 owing to alternative splicing. ${ }^{7}$ After excluding the three sibs, this amounts to an incidence of $\sim 35 \%$ (12/34 alleles) for the mutant allele in our group of patients. When patients previously reported by others are also included, ${ }^{78}$ however, the incidence of this allele approximates $\sim 25 \%$ (15/59 alleles). This makes this allele the most frequently occurring among SLO patients, since all other causative mutations identified to date have been recurrent among a limited number of patients ${ }^{6-8}$ (unpublished results). The RT-PCR based methods presented in this paper provide an easy and rapid screening at the cDNA level for this frequently occurring mutant allele. The allele specific amplification of cDNAs in case of heterozygosity for the $134 \mathrm{bp}$ insertion allows the establishment of compound heterozygosity without subcloning of the cDNAs, which is valuable in cases where no parental material is available.

The relatively high incidence of the splice acceptor site mutation among patients with SLO syndrome remains unexplained at present, but could be the result of a founder effect. This is supported by the complete absence of any of the quite common polymorphisms, ${ }^{7} 189 \mathrm{~A}>\mathrm{G}, 207 \mathrm{C}>\mathrm{T}$, $231 \mathrm{C}>\mathrm{T}, 438 \mathrm{C}>\mathrm{T}, 1158 \mathrm{C}>\mathrm{T}$, and $1272 \mathrm{~T}>\mathrm{C}$, in all 15 mutant alleles identified in our patients. On the other hand, this seems less likely as the allele was identified in unrelated patients of Dutch, German, Belgian, Spanish, and North American origin ${ }^{6-8}$ (this paper).

\section{H R WATERHAM* W OOSTHEIM* G J ROMEIJN* R J A WANDERS* R C M HENNEKAM $†$}

${ }^{\star}$ Laboratory for Genetic Metabolic Diseases (F0-226), Departments of Clinical Chemistry and Paediatrics, Emma Children's Hospital, Academic Medical Centre, University of Amsterdam, PO Box 22700, 1100 DE Amsterdam, The Netherlands

†Department of Paediatrics, Emma Children's Hospital, Academic Medical Centre, University of Amsterdam, PO Box 22700, 1100 DE Amsterdam, The Netherlands

Correspondence to: Dr Waterham, h.r.waterham@amc.uva.nl

1 Smith DW, Lemli L, Opitz JM. A newly recognised syndrome of multiple congenital anomalies. $\mathcal{F}$ Pediatr 1964;64:210-17.

2 Kelley RI. A new face for an old syndrome. Am f Med Genet 1997;65:251-6.

3 Ryan AK, Bartlett K, Clayton P, et al. Smith-Lemli-Opitz syndrome: a variable clinical and biochemical phenotype. F Med Genet 1998;35:558-65.

4 Tint GS, Irons M, Elias ER, et al. Defective cholesterol biosynthesis associated with the Smith-Lemli-Opitz syndrome. N Engl F Med 1994;330:107-13.

5 Schefer S, Salen G, Batta AK, et al. Markedly inhibited 7-dehydrocholesterol- $\Delta$ 7-reductase activity in liver microsomes from 7-dehydrocholesterol- $\Delta$ 7-reductase activity in liver microsom

6 Waterham HR, Wijburg FA, Hennekam RCM, et al. Smith-Lemli-Opitz Waterham HR, Wijburg FA, Hennekam RCM, et al. Smith-Lemli-Opitz
syndrome is caused by mutations in the 7-dehydrocholesterol reductase gene. Am f Hum Genet 1998;63:329-38.

7 Fitzky BU, Witsch-Baumgartner M, Erdel M, et al. Mutations in the $\Delta 7$-sterol reductase gene in patients with the Smith-Lemli-Opitz syndrome. Proc Natl Acad Sci USA 1998;95:8181-6.

8 Wassif CA, Maslen C, Kachilele-Linjewile S, et al. Mutations in the human sterol $\Delta 7$-reductase gene at $11 \mathrm{q} 12-13$ cause Smith-Lemli-Opitz syndrome. Am f Hum Genet 1998;63:55-62.

9 Ijlst L, Wanders RJA, Ushikubo S, et al. Molecular basis of long-chain 3-hydroxyacyl-CoA dehydrogenase deficiency: identification of the major disease-causing mutation in the $\alpha$-subunit of the mitoct

10 Honda M, Tint GS, Honda A, et al. Measurement of $3 \beta$-hydroxysteroid $\Delta 7$-reductase activity in cultured skin fibroblasts utilising ergosterol as a substrate: a new method for the diagnosis of the Smith-Lemli-Opitz substrate: a new method for the diandrome. F Lipid Res 1996;37:2433-8.

11 Van Rooij A, Nijenhuis AA, Wijburg FA, et al. Highly increased CSF concentrations of cholesterol precursors in Smith-Lemli-Opitz syndrome. $\mathcal{F}$ Inherit Metab Dis 1997;20:578-80.

\section{Clinical and molecular cytogenetic studies of a large de novo interstitial deletion 16q11.2-16q21 including the putative transcription factor gene SALL1}

EDITOR-Interstitial deletions of the long arm of chromosome 16 share common clinical features including growth retardation, failure to thrive, microcephaly, high and prominent forehead, prominent metopic suture, large anterior fontanelle, hypertelorism, broad nasal bridge, low set and dysplastic ears, cleft palate, micrognathia, short neck, narrow thorax, broad first toes, mental retardation, muscular hypotonia, congenital heart defects, and gastrointestinal as well as renal anomalies. ${ }^{1}$ More than 26 patients with different interstitial long arm deletions of chromosome 16 have been reported..$^{2-29}$ Recently, mutations in the transcription factor gene SALL1 on chromosome
$16 \mathrm{q} 12.1^{30}$ were shown to result in Townes-Brocks syndrome, an autosomal dominantly inherited malformation syndrome characterised by malformations of the anus, hands, and ears as well as deafness. ${ }^{31}$ We describe a fetus with the 16q deletion syndrome and additional features, including unilateral radial aplasia, ulnar hypoplasia, preaxial hexadactyly, and segmentation defects of the vertebral column. Some of these features overlap with the malformations seen in Townes-Brocks syndrome. We therefore investigated the hypothesis that the SALL1 gene was included within the deletion.

The 31 year old, gravida 2, para 1 (her first child is a healthy boy) was referred at 24 weeks gestation because her fetus had cleft lip and palate detected by ultrasound screening. Biometry showed asymmetrical growth retardation with a thoraco-abdominal diameter of $43 \mathrm{~mm}(<5$ th centile) corresponding to 19 weeks' gestation, while the BPD $(60 \mathrm{~mm})$ and femur length $(41 \mathrm{~mm})$ were within normal limits. Careful examination by ultrasound showed multiple fetal abnormalities. Dilatation of the lateral ventricles, a dilated third ventricle, and a cavum septum pellucidum were noted. Aplasia of the right radius was 


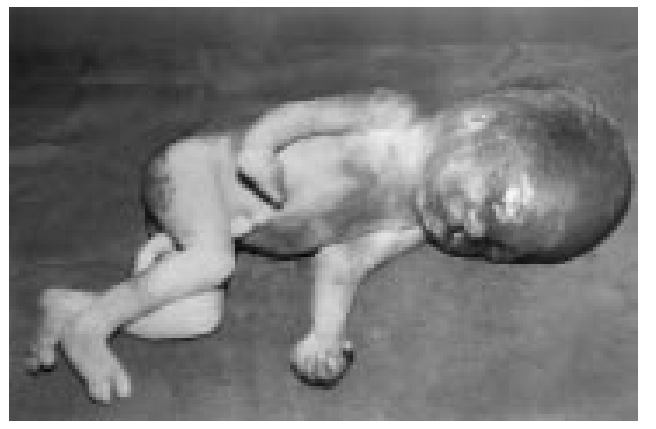

Figure 1 Postmortem picture of the fetus presented. Note the left sided cleft lip/cleft palate, right sided radial aplasia, and a narrow chest.

suspected. The left kidney was absent. The right kidney was supplied by two arteries. The heart showed tetralogy of Fallot with absent pulmonary valve, agenesis of the ductus arteriosus, and a right sided aortic arch. The lungs were hypoplastic. Amniotic fluid, placenta, and umbilical vessels were normal. A fetal blood sample was taken for chromosome analysis. Necropsy examination after the parents opted for termination of the pregnancy in the 25th week of gestation showed a male fetus $31 \mathrm{~cm}$ in length and $690 \mathrm{~g}$ in weight (corresponding to the $24 \mathrm{th} / 25$ th week of gestation). The fetus had a large neurocranium. Facial features included a prominent nasal bridge, a broad nose, hypertelorism, and upward slanting palpebral fissures. The ears were dysplastic, small, and deeply set with a single, left sided preauricular tag. The fetus had left sided cleft lip and palate. The chest was narrow. There was anal stenosis. In the upper extremities, the right radius was absent, while the ulna and thumb were hypoplastic. The left hand displayed preaxial hexadactyly with a finger-like thumb. Crowding of the toes was seen on both feet (figs 1 and 2). $X$ rays confirmed the right radial aplasia and a shortened and thickened ulna. There was a single ossification centre (1 $\mathrm{mm}$ in diameter) within the hypoplastic right thumb, and a single ossification centre (1 $\mathrm{mm}$ in diameter) within the additional left thumb. The distal ossification centre of the additional left thumb was missing. The spine showed multiple segmentation defects (fusion of the third and fourth thoracic vertebral bodies, malformation of the eighth thoracic vertebral body, and aplasia of the third to fifth sacral vertebral bodies). Examination of the heart disclosed a perimembraneous ventricular septal defect $(4 \mathrm{~mm}$ in diameter), aplasia of the semilunar pulmonary valve, agenesis of the ductus arteriosus, and overriding of the right descending aorta. The left kidney was absent.

Chromosome analysis of fetal lymphocytes showed a large interstitial deletion of the long arm of chromosome 16 in all metaphases analysed. The result was confirmed by chromosome analysis of fetal fibroblasts. The karyotypes of the parents were normal. To define the exact site of the deletion, comparative genomic hybridisation $(\mathrm{CGH})$ and fluores-

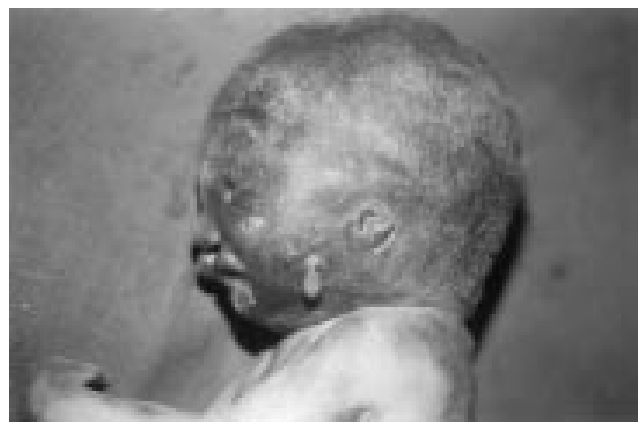

Figure 2 Lateral view of the fetal head. Note the dysplastic, small, and deeply set ears with a single left sided preauricular appendage, and retrognathia.
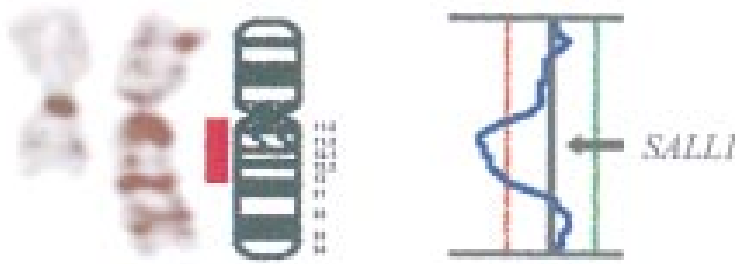

COH analysis

Figure $3 G$ banded chromosomes of fetal fibroblasts and CGH (comparative genomic hybridisation) analysis using fetal DNA showing an interstitial deletion 16q11.2-q21 according to ICSN ${ }^{34}$ as illustrated by the ideogram. Fifteen metaphases were used for CGH analysis. The bar located on the left of the ideogram indicates the deleted region.

cence in situ hybridisation (FISH) analysis were performed. $\mathrm{CGH}$ was performed with fetal DNA as described elsewhere. ${ }^{32} \mathrm{CGH}$ analysis defined the deletion to encompass bands $16 \mathrm{q} 11.2$ to $16 \mathrm{q} 21$ (fig 3). FISH analysis was performed using YACs from within and outside the deletion. YACs 922f01 (D16S415), 965g04 (D16S514/ D16S739), and $957 \mathrm{~h} 03$ (D16S400/D16S3129) residing in 16q12$16 \mathrm{q} 21$ were shown to give only one signal on the normal chromosome 16, but none from the deleted chromosome 16. The STS numbers mapped to the corresponding YAC clones are given in parentheses. YAC 821g09 (D13S3021) located in 16q22 was not deleted. In addition, FISH using a PAC clone (reference: LLNLP704M031126Q4) including the $S A L L 1$ gene $^{33}$ showed heterozygous deletion of $S A L L 1$ (fig 4). DAPI banding confirmed the loss of the whole heterochromatin of chromosome 16 harbouring the deletion. The resulting fetal karyotype was defined as $46, X Y$,del(16)(q11.2;q21) according to ISCN. ${ }^{34}$

The phenotype of the $16 \mathrm{q}$ deletion syndrome was attributed to the deletion of critical bands at 16q11.2-q13, ${ }^{912} 25$ $16 q 21,{ }^{11} 16192124$ and $16 \mathrm{q} 22.1 .{ }^{14}$ Specific features, such as congenital cataract ${ }^{20}$ and iris coloboma, ${ }^{28}$ result from more distal deletions of $16 \mathrm{q} 22.3$ and 16q23.1-24.2. Some of the features documented in patients with proximal deletions of chromosome $16 \mathrm{q}$ are also seen in Townes-Brocks syndrome. ${ }^{313536}$ The clinical presentation of TBS is highly

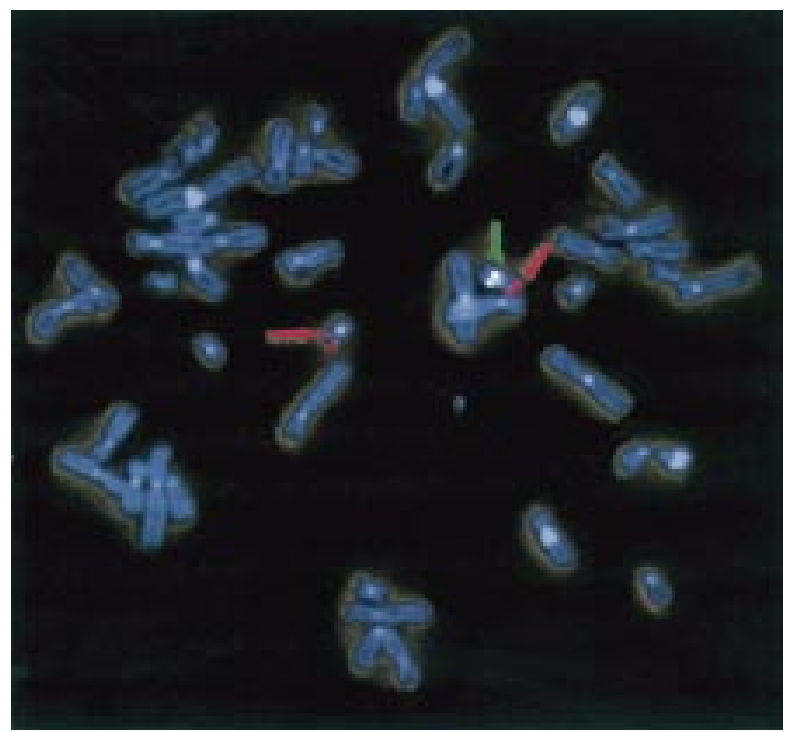

Figure 4 Two colour FISH analysis of fetal metaphase spreads (fibroblasts) using a PAC clone including SALL1. ${ }^{33}$ The signal from the PAC clone, mapping to 16q12.1, gives only one signal on one chromosome 16, while the YAC clone (CEPH 765b06) located on the short arm of chromosome 16 (16p13) shows signals on both chromosomes. 
Table 1 Clinical characteristics of patients with a deletion of the long arm of chromosome 16 including $16 q 12.1$ or $16 q 13$

\begin{tabular}{|c|c|c|c|c|c|c|c|c|}
\hline & \multirow[b]{3}{*}{$\begin{array}{l}\text { Present case } \\
q 11.2 q 21\end{array}$} & \multicolumn{7}{|l|}{ Reference } \\
\hline & & 12 & 17 & 18 & 25 & 11 & 16 & 19 \\
\hline & & $\begin{array}{l}\text { q12.1q13 } \\
\text { (twins) }\end{array}$ & $\begin{array}{l}q 12.1 \\
\text { (sibs) }\end{array}$ & $q 11.1 q 13$ & $q 12.1 q 13$ & $q 13$ & $q 13$ & $q 13 q 21$ \\
\hline Auricular malformation & + & ++ & ++ & + & + & + & + & + \\
\hline Deafness & ? & +- & -- & ? & $\mathrm{SN}$ & & $\mathrm{SN}$ & - \\
\hline Hands & Polydact & Small & $\mathrm{T} \mathrm{T}$ & Small & SC & SC & Small & Polydact \\
\hline Heart defects & + & -+ & -- & + & - & + & - & + \\
\hline Anal malformations & + & +- & -- & - & & - & Ectopic & + \\
\hline Kidney hypo/agenesis & + & -- & ++ & ? & - & + & + & - \\
\hline Malposition of toes & + & ++ & ++ & + & + & + & - & - \\
\hline
\end{tabular}

$\mathrm{SN}=$ sensorineural deafness; polydact = preaxial polydactyly; $\mathrm{T}=$ proximally placed thumbs; $\mathrm{SC}=$ simian creases.

variable ${ }^{37}$ within and between affected families. Characteristic features of TBS are anorectal abnormalities (imperforate anus, ectopic anus), abnormalities of the hands (preaxial polydactyly, triphalangeal thumbs, hypoplastic thumbs), abnormalities of the feet (syndactyly, club foot), deformities of the outer ear ("lop ears") and preauricular tags, and deafness. ${ }^{38}$ Renal malformations include agenesis as well as hypoplastic or polycystic kidneys and may lead to renal failure. ${ }^{39}$ The frequency of cardiac defects in TBS is high in those patients evaluated for cardiac defects by echocardiography. ${ }^{40}$ Mental retardation has rarely been reported. ${ }^{41}{ }^{42}$

TBS is caused by mutations of the SALL1 putative transcription factor gene located on chromosome $16 \mathrm{q} 12.1 .^{30}$ All mutations so far identified in TBS patients ${ }^{33}$ are predicted to result in a prematurely terminated SALL1 protein lacking all double zinc finger domains thought to be essential for SALL1 gene function. Therefore, TBS is strongly suspected to result from haploinsufficiency for SALL1. This hypothesis is strengthened by the observation of a chromosomal translocation and a pericentric inversion in TBS patients, both involving a common breakpoint at $16 \mathrm{q} 12.1$. $^{43}$ The features of the fetus reported here show overlap with TBS. Our FISH studies prove that one allele of SALL1 is indeed deleted. Therefore, we suggest that the ear anomalies, hand anomalies (preaxial polydactyly, hypoplastic thumb), anal stenosis, and the renal agenesis observed in the fetus result from heterozygous deletion of SALL1. The cardiac defects might also result from the SALL1 deletion, since two TBS patients with tetralogy of Fallot have been described previously. ${ }^{45}$ The anomalies of the radius and ulna seen in the fetus most likely result from the deletion of a contiguous gene in the deleted region. Vertebral segmentation defects have only recently been reported in a TBS patient. ${ }^{47}$ However, a SALL1 mutation has not been found in these patients.

Hoo et $a l^{17}$ presented two mentally retarded sisters with a deletion of 16q12.1. Features described in these sisters included dysplastic ears with abnormal folding of the helices, proximally placed thumbs, and bilateral, symmetrically small kidneys. Twins with a deletion of 16q12.2-13 showed ectopic anus, congenital heart defects, and dysplastic ears. ${ }^{12}$ A 10 year old boy with a de novo interstitial deletion $16 \mathrm{q} 12.1 \mathrm{q} 13$ presented with micrognathia, a median cleft, low set dysplastic ears, a preauricular appendage, fusion of the third and fourth and the fifth and sixth vertebrae of the neck, hypospadias, hydrocephalus, sensorineural hearing deficits, and additional dysmorphic features..$^{25}$ Further clinical features described in patients with deletions of the proximal long arm of chromosome 16 are summarised in table 1 . Whether or not SALL1 is deleted in those patients reported with features similar to TBS and with deletions including $16 \mathrm{q} 13$ but not $16 \mathrm{q} 12.1$ remains to be elucidated. ${ }^{11}{ }^{16}{ }^{19}$ Some families have been reported in which affected subjects show features typical of both TBS and Goldenhar syndrome/ oculoauriculovertebral spectrum. ${ }^{48}$ One family was de- scribed with hemifacial microsomia and radial ray defects. ${ }^{50}$ The affected members of this family displayed abnormal ears, multiple preauricular tags and pits, and unilateral micrognathia. In addition, triphalangeal thumbs, unilateral preaxial polydactyly, and a slightly anteriorly placed anus were present. Autosomal dominant inheritance was suggested in this family. Unilateral microphthalmia and facial asymmetry were observed in a family with anteriorly placed anus, irregular toes, and a digitalised thumb. ${ }^{51}$ Gabrielli et a $t^{78}$ described an infant with facial asymmetry, abnormal ears, preauricular tags, and anteriorly placed anus without triphalangeal thumbs or vertebral anomalies. Recently, a SALL1 mutation was detected in the patient described by Gabrielli et $a l^{48}$ showing that SALL1 mutations can also result in a Goldenhar-like phenotype. ${ }^{33}$ It remains to be seen if the affected subjects in the families reported by Johnson et $a l^{49}$ and Moeschler $e t a P^{50}$ also carry mutations in SALL1.

In summary, our results suggest that haploinsufficiency for SALL1 might contribute to TBS-like features seen in the fetus presented here. In addition, certain clinical features in patients with proximal deletions of $16 \mathrm{q}$ including q12.1 are likely to result from haploid SALL1 deletions. Nevertheless, the interstitial deletion in this fetus probably includes several hundred genes, arguing against a simplistic additive genetic model to explain the observed phenotype. Moreover, additional features of the 16q deletion syndrome, which are not part of the phenotypic spectrum of TBS, are likely to be caused by the deletion of additional genes located within the deletion. Some clinical features might be non-specific and cannot be attributed to the deletion of a single gene. FISH studies should indicate whether SALL1 is deleted in those patients reported with features similar to TBS but with deletions including $16 \mathrm{q} 13$ but not 16q12.1. If a SALL1 deletion cannot be confirmed in these patients, a TBS-like phenotype in these patients might still result from a position effect influencing SALL1 gene expression.

Reference address for YACs: http://www.mpimg-berlin-dahlem.mpg.de; http:// www.mpimg-berlin-dahlem.mpg.de/ ctyogen/CHRM16.HTM. We would like to thank Karin Lehmann and Gundula Leschick for expert technical assistance. Dr Friedrich C Luft helped us with the text. This work was funded in part by a grant from the Wilhelm-Sander-Stiftung to JK.

$$
\begin{array}{r}
\text { HANS KNOBLAUCH }{ }^{\star} \\
\text { GUNDULA THIEL } \\
\text { SIGRID TINSCHERT } \\
\text { HANNELORE KÖRNER } \\
\text { HANN } \\
\text { CORNELIA TENNSTEDT } † \\
\text { RABIH CHAOUI } \\
\text { JÜREN KOHLHASE } \\
\text { CHRISTA DIXKENS } \\
\text { CRISTOPHER BLANCK』 }
\end{array}
$$

*Institut für Medizinische Genetik, Universitätsklinikum Charité, 10098 Berlin, Germany

†Institut für Pathologie, Universitätsklinikum Charité, 10098 Berlin, Germany

$\ddagger$ Abteilung für Pränatale Diagnostik und Therapie, Universitätsklinikum Charité, 10098 Berlin, Germany

\Institut für Humangenetik, Universität Göttingen, Heinrich-Düker-Weg, 37073 Göttingen, Germany 
1 Fryns JP, Bande-Knops J, Van den Berghe H. Partial monosomy of the long arm of chromosome 16: a distinct clinical entity? Hum Genet 1979;46:11520 .

2 Brenholz P, Wilmot P, Shapiro LR. Fragile sites on chromosome 16 and the 16q- syndrome. Am f Hum Genet 1982;34:119A.

3 Callen DF, Eyre H, Lane S, et al. High resolution mapping of interstitial long arm deletions of chromosome 16: relationship to phenotype. $7 \mathrm{Med}$ Genet 1993;30:828-32.

4 Carter NP, Ferguson-Smith MA, Perryman MT, et al. Reverse chromosome painting: a method for the rapid analysis of aberrant chromosomes in clinical cytogenetics. F Med Genet 1992;29:299-307.

5 Casamassima AC, Klein RM Wilmot PL, Brenholz P, Shapiro LR. Deletion of $16 \mathrm{q}$ with prolonged survival and unusual radiographic manifestation. Am f Med Genet 1990;37:504-9.

6 Chen CP, Chern SR, Lee CC, Chen LF, Chuang CY. Prenatal diagnosis of de novo interstitial $16 \mathrm{q}$ deletion in a fetus associated with sonographic findings of prominent coronal sutures, a prominent frontal bone, and shortenings of prominent coronal sutures, a prominent fro
ing of the long bones. Prenat Diagn 1998;18:490-5.

7 Cooke A, Tolmie J, Darlington W, Boyd E, Thomson R, Ferguson-Smith MA. Confirmation of a suspected $16 \mathrm{q}$ deletion in a dysmorphic child by MA. Confirmation of a suspected $16 \mathrm{q}$ deletion in a

8 Crawford MN, Punnett HN, Carpenter GG. Deletion of the long arm of chromosome 16 and an unexpected Duffy blood group phenotype reveal a possible autosomal linkage. Nature 1967;215:1075-6.

9 Doco-Fenzy M, Elchardus JF, Brami G, Digeon B, Gruson N, Adnet JJ. Multiple critical smallest region of overlap in monosomy $16 \mathrm{q}$ syndrome. Genet Couns 1994;5:39-44.

10 Duca D, Meilã P, Anca I, et al. Sindroamele cromozomiale 16. Pediatria 1981;30:365-71.

11 Edelhoff S, Maier B, Trautmann U, Pfeiffer RA. Interstitial deletion of 16(q13q22) in a newborn resulting from a paternal insertional translocation. Ann Genet 1991;34:85-9.

12 Elder FFB, Ferguson JW, Lockart LH. Identical twins with deletion 16q syndrome: evidence that $16 \mathrm{q} 12.2-\mathrm{q} 13$ is the critical band region. Hum Genet 1984;67:233-6.

13 Ferguson-Smith MA, Aitken DA. Heterozygosity at the alpha-haptoglobin locus associated with a deletion 16q22-16qter. Cytogenet Cell Genet 1978;22:513.

14 Fujiwara $M$, Yoshimoto $T$, Morita $Y$, Kamada M. Interstitial deletion of chromosome 16q: $16 \mathrm{q} 22$ is critical for 16q- syndrome. Am 7 Med Genet 1992;43:561-4.

15 Fryns JP, Melchior S, Jaeken J, Van den Berghe H. Partial monosomy of the long arm of chromosome 16 in a malformed newborn: karyotype 46,XX,del(16)(q21). Hum Genet 1977;38:343-6.

16 Fryns JP, Proesmans W, Van Hoey G, Van den Berghe H. Interstitial 16q deletion with typical dysmorphic syndrome. Ann Genet 1981;24:124-5.

17 Hoo JJ, Lowry RB, Lin CC, Haslam RHA. Recurrent de novo interstitial deletions of $16 \mathrm{q}$ in two mentally retarded sisters. Clin Genet 1985;27:420-5.

18 Krauss CM, Caldwell D, Atkins L. Interstitial deletion and ring chromosome derived from 16q. F Med Genet 1987;24:308-12.

19 Lin CC, Lowry RB, Snyder FF. Interstitial deletion for a region in the long arm of chromosome 16. Hum Genet 1983;65:134-8.

20 Monaghan KG, Van Dyke DL, Wiktor A, Feldman GL. Cytogenetic and clinical findings in a patient with a deletion of $16 \mathrm{q} 23.1$ : first report of bilateral cataracts and a 16q deletion. Am f Med Genet 1997;73:180-3.

21 Naritomi K, Shimora N, Izumikawa Y, Sameshima K, Ohdo S, Hirayama K. $16 \mathrm{q} 21$ is critical for the 16q deletion syndrome. Clin Genet 1988;33:372-5.

$16 \mathrm{q} 21$ is critical for the 16q deletion syndrome. Clin Genet 1988;33:372-5.
Natt E, Westphal EM, Toth-Fejel SE, et al. Inherited and de novo deletion of the tyrosine aminotransferase gene locus at 16q22.1-q22.3 in a patient with tyrosinemia type II. Hum Genet 1987;77:352-8.

23 Natt E, Magenis RE, Zimmer J, Mansouri A, Scherer G. Regional assignment of the human loci for uvomorulin (UVO) and chymotrypsin B (CTRB) with the help of two overlapping deletions on the long arm of chromosome 16. Cytogenet Cell Genet 1989;50:145-8.

24 Rivera H, Vargas-Moyeda E, Möller M, Torres-Lamas A, Cantú JM. Monosomy 16q: a distinct syndrome. Clin Genet 1985;28:84-6.

25 Schuffenhauer S, Callen DF, Seidel H, Shen Y, Lederer G, Murken J. De novo interstitial deletion $16(\mathrm{q} 12.1 \mathrm{q} 13)$ of paternal origin in a 10 -year-old boy. Clin Genet 1992;42:246-58.
26 Taysi K, Fishman M, Sekhons GS. A terminal long arm deletion of chromosome 16 in a dysmorphic infant: 46,XY,del(16)(q22). Birth Defects 1978;XIV(6C):343-7.

27 Trautmann U, Pfeiffer RA, Seufert-Satomi U, Tietze HU. Simultaneous de novo interstitial deletion of $16 \mathrm{q} 21$ and intercalary duplication of $19 \mathrm{q}$ in a retarded infant with minor dysmorphic features. F Med Genet 1993;30:330-1.

28 Werner W, Kraft S, Callen DF, Bartsch O, Hinkel GK. A small deletion of 16q23.1-16q24.2 (del(16)(q23.1q24.2).ish $\operatorname{del}(16)(\mathrm{q} 23.1 \mathrm{q} 24.2)$ (D16S395+, D16S348-, P5432)) in a boy with iris coloboma and minor anomalies. Am f Med Genet 1997;70:371-6.

29 Witt DR, Lew SP, Mann J. Heritable deletion of band 16q21 with normal phenotype relationship to late replicating DNA. Am f Hum Genet 1988;43: A127.

30 Kohlhase J, Wischermann A, Reichenbach H, Froster U, Engel W. Mutations in the SALL1 putative transcription factor gene cause TownesBrocks syndrome. Nat Genet 1998;18:81-3.

31 Townes PL, Brocks ER. Hereditary syndrome of imperforate anus with hand, foot, and ear anomalies. F Pediatr 1972;81:321-6.

32 Schröck E, Thiel G, Lozanova T, et al. Comparative genomic hybridization of human malignant gliomas reveals multiple amplification sites and nonrandom chromosomal gains and losses. Am f Pathol 1994;144:1203-17.

33 Kohlhase J, Taschner PE, Burfeind P, et al. Molecular analysis of SALL1 mutations in Townes-Brocks syndrome. Am f Hum Genet 1999;64:435-45.

34 ISCN 1995. In: Mitelman F, ed. An international system for human cytogenetic nomenclature. Basel: S Karger, 1995

35 Wischermann A, Holschneider AM. Townes-Brocks-Syndrom. Monatsschr Kinderheilkd 1997;145:382-6.

36 Powell CM, Michaelis RC. Townes-Brocks syndrome. 7 Med Genet 1999;36:89-93.

37 De Pina-Neto J. Phenotypic variability in Townes-Brocks syndrome. Am 7 Med Genet 1984;18:147-52.

38 Rossmiller DR, Pasic TR. Hearing loss in Townes-Brocks syndrome. Otolaryngol Head Neck Surg 1994;111:175-80.

39 Newman WG, Brunet MD, Donnai D. Townes-Brocks syndrome presenting as end stage renal failure. Clin Dysmorphol 1997;6:57-60.

40 O'Callaghan M, Young ID. The Townes-Brocks syndrome. 7 Med Genet 1990;27:457-61.

41 Cameron TH, Lachiewicz AM, Aylsworth AS. Townes-Brocks syndrome in two mentally retarded youngsters. Am f Med Genet 1991;41:1-4.

42 Ishikiriyama S, Kudoh F, Shimojo N, Iwai J, Inoue T. Townes-Brocks syndrome associated with mental retardation. Am f Med Genet 1996;61:191-2.

43 Friedman P, Rao K, Aylsworth A. Six patients with the Townes-Brocks syndrome including five familial cases with a pericentric inversion of chromosome 16. Am f Hum Genet Suppl 1987;41:A60.

44 Serville F, Lacombe D, Saura R, Billeaud C, Sergent, MP. Townes-Brocks syndrome in an infant with translocation t(5;16). Genet Couns 1993;4: 109-12.

45 Hersch JH, Jaworski M, Solinger RE, Weisskopf B, Donat J. Townes syndrome: a distinct multiple malformation syndrome resembling VACTERL association. Clin Genet 1986;25:100-2

46 Parent $\mathrm{P}$, Bensaid $\mathrm{M}$, LeGuern $\mathrm{H}$, et al. Clinical heterogeneity of Townes-Brocks syndrome. Arch Pediatr 1995;2:551-4

47 Marlin S, Toublanc JE, Petit C. Two cases of Townes-Brocks syndrome with previously undescribed anomalies. Clin Dysmorphol 1998;7:295-8

48 Gabrielli O, Bonifazi V, Offidani AM, Cellini A, Coppa GV, Giorgi PL. Description of a patient with difficult nosological classification: Goldenhar syndrome or Townes-Brocks syndrome. Minerva Pediatr 1993;45:459-62.

49 Johnson JP, Poskanzer L, Sherman S. Three-generation family with resemblance to Townes-Brocks syndrome and Goldenhar/oculo-auriculovertebral spectrum. Am 7 Med Genet 1996;61:134-9.

50 Moeschler J, Clarren SK. Familial occurrence of hemifacial microsomia with radial limb defects. Am F Med Genet 1982;12:371-5.

51 Fraser FC, Cooper AR. Micropthalmia as part of the Townes (sic) syndrome. Proc Greenwood Genet Centre 1985;4:129.

\section{Oculocutaneous albinism type 2 with a $P$ gene missense mutation in a patient with Angelman syndrome}

EDITOR-Oculocutaneous albinism type 2 (OCA2) is an autosomal recessive disorder characterised by defective melanin production of the skin, hair, and eyes, ${ }^{1}$ which is caused by mutations of the $P$ gene. ${ }^{2}{ }^{3}$ The specific function of $P$ has not been clarified, although it is likely to act as a transporter in the melanosomal membrane. ${ }^{24}$

The $P$ gene is located in 15q11-q13, which is deleted in the majority of patients with Angelman syndrome (AS) and Prader-Willi syndrome (PWS). ${ }^{25}$ The $P$ gene is not imprinted and both alleles are expressed. PWS and AS patients with typical deletions are thus hemizygous for $P$. It is also well established that AS and PWS deletion patients usu- f Med Genet 2000;37:392-394

ally show hypopigmentation of the skin and hair, and $P$ is suggested to be responsible for this hypopigmentation as well, ${ }^{67}$ although the mechanism has not yet been established.

A small intragenic deletion and a V443I missense mutation of the $P$ gene were identified in the maternally inherited alleles of two PWS plus OCA2 patients who had a paternally inherited deletion of $15 \mathrm{q} 11-\mathrm{q} 13 .^{23}$ Here we describe the first evidence that a $P$ gene mutation is responsible for OCA2 associated with AS.

The male patient was born at 38 weeks' gestation to unrelated Japanese parents. There were no complications of pregnancy or delivery, but the birth weight, $1850 \mathrm{~g}$, was small for gestational dates. Generalised albinism was noted at birth. Motor development was delayed, and he had a generalised tonic-clonic convulsion at the age of 18 months. He was admitted to hospital at the age of 19 months because of non-convulsive epileptic status, as reported previously. ${ }^{8}$ Physical examination showed the 

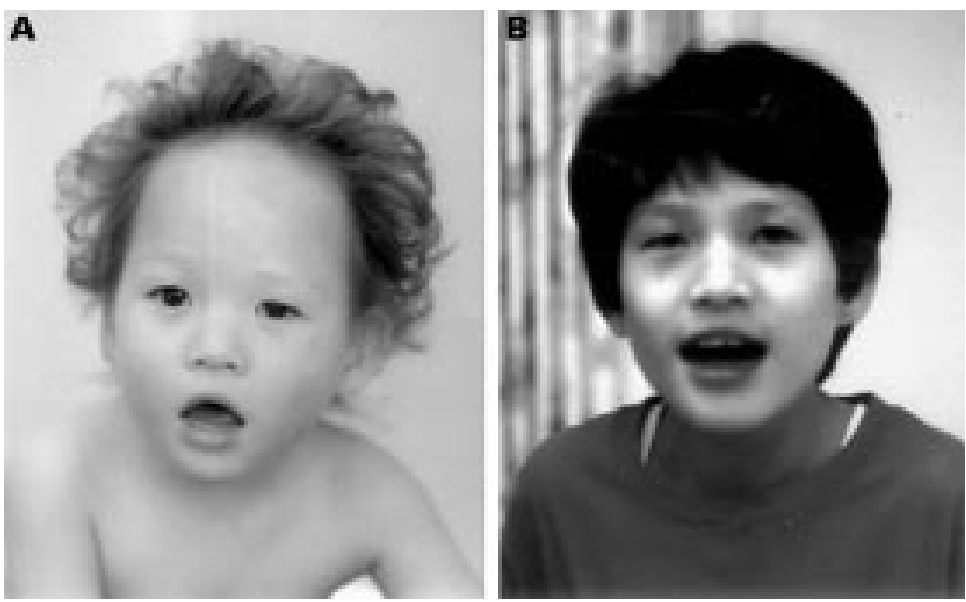

Figure 1 Phenotypic appearance of the patient at (A) 2 years of age and (B) 12 years of age.

typical facies of AS, including prominent mandible, protruding tongue, and relatively small head circumference $(-1.72 \mathrm{SD})$. His skin and hair pigmentation was markedly reduced consistent with albinism (fig 1A). His hair colour was fair-blonde. Ophthalmological examination showed reduced pigmentation of the iris and a tigroid appearance of the retina with mildly reduced pigmentation. There was no nystagmus or other visual problems. He began walking unassisted at the age of 9 years with an ataxic gait typical of AS with the "hands up" position. He had severe mental retardation and could not speak. His skin, hair, and eye pigmentation gradually increased and he had dark hair by 12 years of age (fig 1B). His father and brother showed mild hypopigmentation of the skin and hair compared with other family members.

High resolution chromosome analysis and fluorescence in situ hybridisation (FISH) using D15S10 (Vysis, Downers Grove, Illinois) as probe showed a karyotype 46,XY,del(15) (q11q13) in the patient. Parental origin of the deletion was studied by the DNA methylation test using SNRPN exon 1 as probe. ${ }^{9}$ Genomic DNA was extracted from the patient and parents by a standard procedure. ${ }^{9}$ The $S N R P N$ DNA methylation test indicated that the patient had only a paternal methylation pattern, indicating a maternal origin of the deletion (data not shown). These molecular cytogenetic results confirmed the clinical diagnosis of AS.

To screen for a $P$ gene mutation, all 25 exons and flanking introns of the $P$ gene were amplified by polymerase chain reaction (PCR) using the primers described by Lee $e t$ $a l,{ }^{4}$ agarose gel purified with GFX PCR and Gel Band Purification Kit (Amersham Pharmacia Biotech, Uppsala,
Sweden), and direct sequenced with the ABI PRISM BigDye Terminator Cycle Sequencing Ready Reaction Kit. Sequence reactions were run on a Perkin-Elmer 310 Automatic Sequencer and analysed by use of LASERGENE software (DNASTAR, Madison, WI). A missense mutation A481T $(1441 \mathrm{G}>\mathrm{A})$ as well as non-pathological polymorphisms (IVS11-4A $>$ G, G780G $(2340 \mathrm{C}>\mathrm{T}$ ), S788S (2364G $>$ A)) of the $P$ gene were identified in the patient (fig 2). The $1441 \mathrm{G}>\mathrm{A}$ mutation is located in exon 14 of $P$ and causes amino acid substitution of alanine for threonine at codon 481. The non-pathological polymorphisms have been previously described in other people. ${ }^{4}$ No wild type sequence was identified at these positions in the patient, as expected with hemizygosity at this locus. The father was shown to be heterozygous for the A481T mutation, whereas the mother was homozygous for the wild type allele (fig 2).

In this study the AS patient with OCA2 was shown to have a typical large deletion on the maternally inherited chromosome $15 \mathrm{q}$, and a missense $P$ mutation (A481T) on the paternally inherited chromosome. Most AS and PWS deletions are of similar size and $P$ is always deleted in these patients. ${ }^{5}$ Since the patient has only the A481T mutation allele, the mother is homozygous for the normal allele, and the father is heterozygous for the A481T mutation allele and the normal allele, the maternally inherited $P$ allele must be deleted in the patient. This was confirmed for the deletion origin by methylation analysis with the adjacent imprinted region of $15 \mathrm{q} 11-\mathrm{q} 13$.

AS patients with the common $15 \mathrm{q}$ deletion are frequently associated with hypopigmentation, whereas other classes of AS patients are less often hypopigmented..$^{11}$ Similarly,
Patient

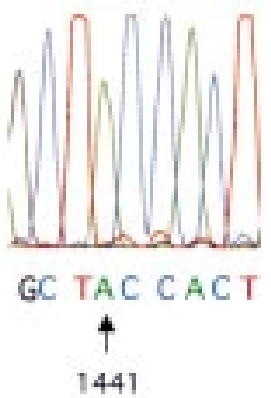

Father

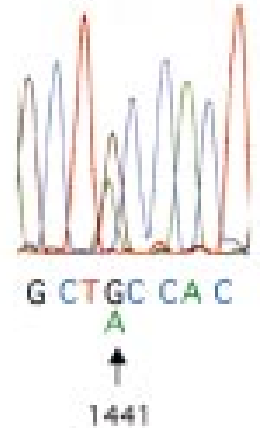

Mother

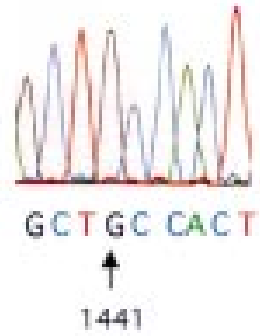

Figure 2 Segregation of the missense mutation in the patient and parents. The arrow indicates the position of the base substitution. The number below the arrow (1441) indicates the corresponding cDNA nucleotide position adapted from Lee et al. ${ }^{4}$ 
hypopigmentation in PWS also correlates with $P$ deletion. ${ }^{7} \mathrm{~A}$ hemizygous deletion of $P$ cannot completely explain the mild degree of hypopigmentation more commonly seen in AS or PWS because heterozygous carriers of severe autosomal recessive OCA2 patients do not usually have hypopigmentation. Therefore, one can speculate that a pigmentation modifier gene(s) may be present in the deleted region of 15q11-q13.

The A481T mutation has previously been found in an African-American patient with $P$ related autosomal recessive ocular albinism, ${ }^{3}$ as well as in one of 50 unrelated controls. ${ }^{4}$ The frequency of OCA2 is approximately $1 / 40000$ and $1 / 10000$ in whites and in AfricanAmericans, respectively. ${ }^{12}$ Carrier frequency is thus estimated to be 1/50-1/100. The carrier frequency of A $481 \mathrm{~T}$ reported by Lee $e t a l^{4}$ may have been overestimated, since previous studies have not shown that A481T is a predominant mutation in OCA2.. ${ }^{3213}$

The function of the A481T allele was shown by transfecting A481T mutant $P$ cDNA into $p$ null mouse melanocytes, ${ }^{14}$ which showed that the A481T allele had approximately $70 \%$ function of the wild type allele. Therefore, since our patient is hemizygous, he may only have $35 \%$ of $P$ gene function in melanin production compared with the wild type.

Our patient showed a severe deficiency of pigmentation during infancy to early childhood, but melanin production gradually increased and he had dark hair by 12 years of age. This is in keeping with the natural history of OCA2, as gradual increase in pigmentation during childhood is commonly seen in OCA2 patients. These findings are also consistent with the finding that the A481T allele has the potential for producing significant amounts of melanin as shown in the tissue culture experiments. Many mammalian genes are known to have an effect on pigmentation ${ }^{15}$ and are developmentally controlled, although the precise mechanisms have not been established. Possible deletion of other pigmentation modifier gene(s) located in $15 \mathrm{q}$ may also explain the profound hypopigmentation in our patient during early childhood.

In conclusion, we describe the first genetic evidence that the $P$ gene mutation is responsible for OCA2 associated with AS. These findings increase the spectrum of clinical conditions (AS or PWS plus OCA2, OCA2, ocular albinism) associated with $P$ gene mutations.
The authors thank Drs K Kobayashi, R D Nicholls, and R A Spritz for critical comments on the manuscript. This work was supported by the Research Grant $(8 \mathrm{~A}-8)$ for Nervous and Mental Disorders from the Ministry of Health and Welfare of Japan (SS), by grant in aid No 09470190 from the Ministry of Education, Science and Culture of Japan (KF), and by the Mochida Memorial Foundation for Medical and Pharmaceutical Research (KF).

SHINJI SAITOH*

NAOKI OISO +

TAKAHITO WADA* OSAMU NARAZAKI KAZUYOSHI FUKAI $\dagger$

*Department of Paediatrics, Hokkaido University School of Medicine, Kita 15, Nishi 7, Kita-ku, Sapporo 060-8638, Fapan

†Department of Dermatology, Osaka City University Medical School, Osaka, Fapan

$\ddagger$ Department of Paediatric Neurology, Fukuoka Children's Hospital Medical Centre, Fukuoka, Fapan

Correspondence to: Dr Saitoh, ss11@med.hokudai.ac.jp

1 Spritz RA. Molecular genetics of human oculocutaneous albinism. Hum Mol Genet 1994;3:1469-75.

2 Rinchik EM, Bultman SJ, Horsthemke B, et al. A gene for the mouse pinkeyed dilution locus and for human type II oculocutaneous albinism. Nature 1993;361:72-6

3 Lee ST, Nicholls RD, Bundey S, Laxova R, Musarella M, Spritz RA. Mutations of the $P$ gene in oculocutaneous albinism, ocular albinism, and Prader-Willi syndrome plus albinism. N Engl f Med 1994;330:529-34.

4 Lee ST, Nicholls RD, Jong MT, Fukai K, Spritz RA. Organization and sequence of the human $P$ gene and identification of a new family of transsequence of the human $P$ gene and identifica

5 Nicholls RD, Saitoh S, Horsthemke B. Imprinting in Prader-Willi and Nicholls RD, Saitoh S, Horsthemke B. Imprinting
Angelman syndromes. Trends Genet 1998;14:194-200.

6 Clayton-Smith J. Clinical research on Angelman syndrome in the United Kingdom: observations on 82 affected individuals. Am f Med Genet 1993; 46:12-15.

7 Spritz RA, Bailin T, Nicholls RD, et al. Hypopigmentation in the Prader-Willi syndrome correlates with $P$ gene deletion but not with haplotype of the hemizygous $P$ allele. Am 7 Med Genet 1997;71:57-62.

8 Ise K, Hanai T, Narazaki O. Two cases of Angelman syndrome with minor epileptic status. $\mathcal{F}$ fpn Epil Soc 1992;10:241-8.

9 Glenn CC, Saitoh S, Jong MT, et al. Gene structure, DNA methylation, and Glenn CC, Saitoh S, Jong MT, et al. Gene structure, DNA methylation, and
imprinted expression of the human SNRPN gene. Am f Hum Genet 1996; 58:335-46.

10 Saitoh S, Harada N, Jinno Y, et al. A molecular and clinical study of 61 Angelman syndrome patients. Am $\mathcal{F}$ Med Genet 1994;52:158-63.

11 Smith A, Wiles C, Haan E, et al. Clinical features in 27 patients with Angelman syndrome resulting from DNA deletion. F Med Genet 1996;33:107-12.

12 Oetting WS, Gardner JM, Fryer JP, et al. Mutations of the human P gene associated with type II oculocutaneous albinism (OCA2). Hum Mutat 1998;205:online.

13 Spritz RA, Lee ST, Fukai K, et al. Novel mutations of the $P$ gene in type II oculocutaneous albinism. Hum Mutat 1997;10:175-7.

14 Sviderskaya EV, Bennett DC, Ho L, Bailin T, Lee ST, Spritz RA. Complementation of hypopigmentation in $p$-mutant (pink-eyed dilution) mouse melanocytes by normal human $P$ cDNA, and defective complementation by OCA2 mutant sequences. F Invest Dermatol 1997;108:30-4.

15 Jackson IJ. Homologous pigmentation mutations in human, mouse and other model organisms. Hum Mol Genet 1997;6:1613-24.

\section{Anticipation in progressive diaphyseal dysplasia}

EDITOR-Progressive diaphyseal dysplasia (MIM 131300) is an autosomal dominant osteochondrodysplasia with late onset and marked variability in expression of clinical and radiological features. ${ }^{1}$ We have recently described a patient with this diagnosis and suggested the presence of anticipation, ${ }^{2}$ the tendency of a familial disorder to occur earlier in the younger than in the older generations of a family. ${ }^{3}$

In order to assess whether this hypothesis were true, we examined 24 other people from the same family (fig 1) who were invited and agreed to participate. We excluded the proband and tried to avoid ascertainment bias by including in the study all family members who were alive in four generations. Although the diagnosis of progressive diaphyseal dysplasia had not been previously recorded in any of them, some family members had assigned to themselves the status of affected or unaffected. This was often discordant with the clinical and radiological data. It is also likely that people with bone complaints were more eager to consent to medical observation.

All family members were personally examined. The presence or absence and the age of onset of pain in the limbs, easy fatiguability, headache, poor appetite, and difficulty in running were recorded. Height, weight, and OFC were determined. Skull, spine, and limb morphology was examined and exophthalmos, muscle mass and strength, joint movement, tendon reflexes, and walking were assessed. Bone radiographic surveys, haemoglobin, white blood cell count, erythrocyte sedimentation rate, and serum alkaline phosphatase were performed.

The diagnosis of progressive diaphyseal dysplasia was clinically and radiologically established in 15 family members of the proband (table 1). Five of these have been previously described. ${ }^{2}$ 


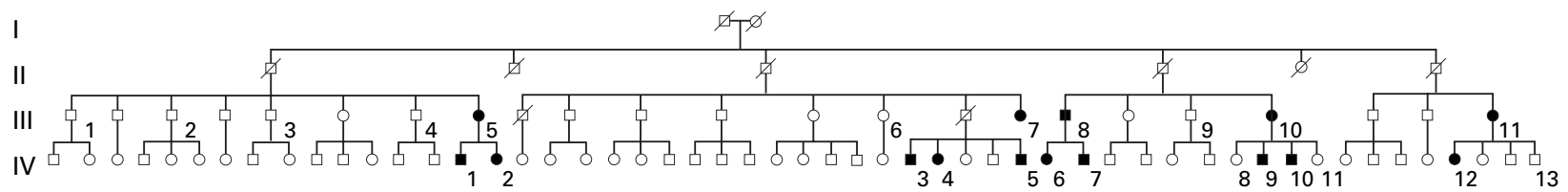

Figure 1 Pedigree showing 15 cases of progressive diaphyseal dysplasia in generations III and IV of one family. Only those personally examined are numbered and included in the statistical analysis.

Table 1 Clinical, laboratory, and radiographic data from 15 patients with progressive diaphyseal dysplasia

\begin{tabular}{|c|c|c|c|c|c|c|c|c|c|c|c|c|c|c|c|}
\hline & \multicolumn{15}{|c|}{ Patient } \\
\hline & III. 5 & III. 7 & III. 8 & III. 10 & III. 11 & IV.1 & $I V .2$ & $I V .3$ & $I V .4$ & IV.5 & IV.6 & IV.7 & $I V .9$ & IV.10 & IV.12 \\
\hline Age at onset of symptoms (y) & 30 & 20 & 20 & 15 & 21 & 15 & 14 & 3 & 10 & 10 & 8 & 5 & 18 & 13 & 2 \\
\hline Age at examination $(\mathrm{y})$ & 54 & 64 & 51 & 42 & 47 & 25 & 16 & 36 & 34 & 29 & 23 & 8 & 20 & 16 & 26 \\
\hline Pain in limbs & PMo & PMi & PMi & PMi & PMi & PMi & PMi & PMo & PMo & PMo & PMo & PMi & A & A & PS \\
\hline Easy fatiguability & PMo & $\mathrm{PMi}$ & A & PMi & A & $\mathrm{PMi}$ & A & PMo & $\mathrm{PMi}$ & PMo & PMo & A & A & $\mathrm{PMi}$ & PMo \\
\hline Headache & A & A & A & PMi & A & A & PMi & A & PMi & A & A & A & PMi & A & A \\
\hline Poor appetite & A & A & A & PMi & A & $\mathrm{PMi}$ & A & A & A & A & A & A & A & A & PMi \\
\hline Poor muscle mass & A & A & A & A & A & A & A & $\mathrm{PMi}$ & A & PMo & A & $\mathrm{PMi}$ & A & A & PMo \\
\hline Waddling gait & PMi & PMi & A & A & A & PMi & A & $\mathrm{PMi}$ & $\mathrm{PMi}$ & PMo & PMo & A & A & A & PS \\
\hline Radiographic bone changes & PMo & PS & PMo & PMo & PMi & PMo & PMi & PS & PS & PS & PS & $\mathrm{PMi}$ & $\mathrm{PMi}$ & PMi & PS \\
\hline Haemoglobin $(\mathrm{g} / \mathrm{dl})$ & 13.6 & 13.2 & 14.9 & 12.9 & 12.9 & 15.3 & 13.3 & 13.7 & 14.5 & 14.6 & 13.3 & 12.8 & 13.9 & 14.7 & 13.7 \\
\hline Erythrocyte sedimentation rate $\mathrm{mm} / \mathrm{h}$ & 14 & 28 & 1 & 3 & 11 & 9 & 11 & 13 & 16 & 15 & 6 & 11 & 10 & 4 & 16 \\
\hline Alkaline phosphatase $(\mathrm{U} / \mathrm{l})$ & 27 & 42 & 81 & 24 & 33 & 28 & 20 & 35 & 52 & 57 & 203 & 105 & 46 & 71 & 97 \\
\hline
\end{tabular}

P, present; A, absent; S, severe; Mo, moderate; Mi, mild.

We were able to determine the age of onset of the disease in these 15 patients (table 1), five from generation III and 10 from generation IV. Age of onset of the disease was defined as that of the initial symptom. The earlier age of onset in the younger generation was statistically significant (table 2). A similar analysis applying the same criteria to the data previously described in another extended family with progressive diaphyseal dysplasia ${ }^{4}$ gave identical results (table 2). Other published pedigrees do not describe large families and often do not mention the age of onset of the disease. ${ }^{5-10}$. However, the available data, excluding once again the probands, is in accordance with the previous results (table 2).

A previous suggestion that anticipation was enhanced in father to son transmission ${ }^{2}$ is not supported by these new data; the patient with the earliest age of onset and one of the most severely affected is a female (IV.12, fig 1, table 1), who inherited the disease from her mother.

As has been previously pointed out, statistical anticipation without biological anticipation would occur if the disorder reduces fertility. ${ }^{3}$ However, the mean number of children in the family members of generation III is 2 for those that are healthy and 2.8 for those that are affected. The small number of people of generation IV who have already had children does not merit consideration.

Another type of bias could be that some of the younger persons might be classed as unaffected but might develop the disease later. This would inevitably increase the mean age of onset as assessed in the younger generation. However, the reported ages of onset of progressive diaphyseal dysplasia are between 4 and 32 years and in 25 patients all but four had ages of onset younger than 20, the exceptions being the ages of $21,25,30$, and 32 years old. ${ }^{24}$ In order to avoid this bias,

Table 2 Mean age of onset of progressive diaphyseal dysplasia in the older and younger generations in the family described here (family 1), the family reported by Naveh et al ${ }^{4}$ (family 2), and other pedigrees ${ }^{5-1}$

\begin{tabular}{llllll}
\hline & & Number & Mean & $S D$ & \multirow{2}{*}{$p$} \\
\hline Family 1 & Older generation & 5 & 21.2 & 5.4 & \\
& Younger generation & 10 & 9.8 & 5.3 & 0.001903 \\
Family 2 & Older generation & 5 & 18.0 & 10.2 & \\
& Younger generation & 5 & 4.2 & 3.1 & 0.020079 \\
Families 1 and 2 & Older generation & 10 & 19.6 & 7.9 & \\
& Younger generation & 15 & 7.9 & 5.3 & 0.000195 \\
Other pedigrees & Older generation & 7 & 21.4 & 10.5 & \\
& Younger generation & 5 & 3.0 & 1.9 & 0.003419 \\
& & & & &
\end{tabular}

we did not include the data on three persons, one of whom is affected, from generation V. The ages of the unaffected persons from generation IV are 16, 23, and 24 years.

Although anticipation was only accepted as a true biological concept in the last decade, the list of conditions exhibiting it is growing rapidly. ${ }^{311}$ Most of them are neuropsychiatric diseases and trinucleotide repeat expansions are usually suggested to be the cause.

This report suggests that anticipation occurs in progressive diaphyseal dysplasia and widens the disease spectrum of this concept to bone dysplasias. A dynamic mutation with trinucleotide repeat expansion may or may not be the cause of this osteochondrodysplasia of dense bone with unknown pathogenesis. The search for the molecular explanation of this and other rare genetic disorders that cause dense bones could disclose approaches to more common health problems such as osteoporosis. ${ }^{12}$

This work was supported by the Comissão de Fomento da Investigação em Cuidados de Saúde, Ministério da Saúde, Portugal.

JORGE M SARAIVA

Consulta de Genética, Hospital Pediátrico de Coimbra, and Serviço de

Genética Médica, Faculdade de Medicina de Coimbra, Avenida

Bissaya-Barreto,3000Coimbra,Portugal,hpcgen@hotmail.com

1 McKusick VA. Mendelian inheritance in man: a catalog of human genes and genetic disorders. 12th ed. Baltimore: The Johns Hopkins University Press, 1998.

2 Saraiva JM. Progressive diaphyseal dysplasia - a three generation family with markedly variable expressivity. Am $\mathcal{f}$ Med Genet 1997;71:348-52.

3 Fraser FC. Trinucleotide repeats not the only cause of anticipation. Lancet 1997;350:459-60.

4 Naveh Y, Kaftori JK, Alon U, Ben-David J, Berant M. Progressive diaphyseal dysplasia: genetics and clinical and radiological manifestations. Pediatrics 1984;74:399-405.

5 Girdany BR. Engelmann's disease (progressive diaphyseal dysplasia) - a nonprogressive familial form of muscular dystrophy with characteristic bone changes. Clin Orthop 1959;14:102-9.

6 Ruelle M, Dubois JL. A propos de deux cas familiaux de sclerose diaphysaire multiple (syndrome de Camurati-Engelmann). Rev Rhum Mal diaphysaire multiple (syn
Osteoartic 1964;31:345-8.

7 Anczykowa A, Bernasowska-Knapczykowa K, Zamorska L. CamuratiEngelmann's disease in three siblings. Polski Przglad Radiologiczny 1967;31: 165-78

8 Trunk G, Newman A, Davis TE. Progressive and hereditary diaphyseal dysplasia - Engelmann's disease. Arch Intern Med 1969;123:417-22.

Sparkes RS, Graham CB. Camurati-Engelmann disease - genetics and clinical manifestations with a review of the literature. $f$ Med Genet 1972;9:73-85.

10 Hundley JD, Wilson FC. Progressive diaphyseal dysplasia - review of the literature and report of seven cases in one family. F Bone foint Surg Am 1973; 55:461-74.

11 McInnis MG. Anticipation: an old idea in new genes. Am f Hum Genet 1996;59:973-9.

12 Whyte MP. Searching for gene defects that cause high bone mass. Am f Hum Genet 1997;60:1309-11. 


\section{Hereditary neuropathy with liability to pressure palsies: two cases with a reciprocal translocation $\mathrm{t}(16 ; 17)(\mathrm{q} 12 ; \mathrm{p} 11.2)$ interrupting the PMP22 gene}

EdITOR-Hereditary neuropathy with liability to pressure palsies (HNPP) or tomaculous neuropathy is an autosomal dominant disease. ${ }^{1}$ HNPP patients present with acute or recurrent transient muscle palsies and paraesthesias, usually after minor trauma. HNPP is characterised from the pathological point of view by the presence of sausage shaped swelling of the myelin sheath or tomacula ${ }^{2}$ in sensory and motor nerves.

A deletion on the proximal short arm of chromosome 17 was detected in affected members of HNPP families. ${ }^{4}$ The deleted region is the same as that duplicated in Charcot-Marie-Tooth disease type 1 (CMT1A). While the CMT1A phenotype is mostly the result of extra dosage of the genes contained in this duplicated region, the HNPP phenotype results from monosomy of the same region in over $85 \%$ of cases. ${ }^{6}$ This duplication/deletion event is thought to occur because of the unequal crossing over between two large repeats bordering the CMT1A region, ${ }^{7}$ which encompasses $1.5 \mathrm{Mb}$ of $17 \mathrm{p} 11.2 .^{8}$

The association between CMT1A and the peripheral myelin protein 22 (PMP22) gene, located within the CMT1A duplicated region, was established by the finding of point mutations in this gene ${ }^{910}$ in CMT1A patients. The PMP22 gene spans approximately $40 \mathrm{~kb}$ and contains four coding and two 5 ' untranslated (1A and $1 \mathrm{~B}$ ) exons. ${ }^{11}$ In 35 unrelated patients with inherited peripheral neuropathies, 27 mutations in the PMP22 gene have been described, affecting the different domains of the protein, ${ }^{12}$ some of them leading to a truncated protein. The clinical phenotypes of the patients carrying mutations in the $P M P 22$ gene are variable, giving some clues about correlations between phenotype and genotype. Five mutations in the PMP22 gene have been described that result in a HNPP phenotype: two frameshift mutations, ${ }^{13}{ }^{14}$ two nonsense mutations, ${ }^{15}{ }^{16}$ and a splice site mutation. ${ }^{17}$

We report here a pedigree with two affected members (mother and son) with HNPP, both of whom carry a reciprocal translocation $\mathrm{t}(16 ; 17)(\mathrm{q} 12 ; \mathrm{p} 11.2)$, which we have

Table 1 Electroneurographic findings in two patients with hereditary neuropathy with liability to pressure palsies (HNPP)

\begin{tabular}{|c|c|c|c|c|c|c|}
\hline & \multicolumn{6}{|c|}{ Motor and sensory nerve conduction } \\
\hline & \multicolumn{2}{|c|}{ Ulnar nerve } & \multicolumn{2}{|c|}{ Median nerve } & \multicolumn{2}{|c|}{ Peroneal nerve } \\
\hline & $P$ & $M$ & $P$ & $M$ & $P$ & $M$ \\
\hline \multicolumn{7}{|c|}{$\mathrm{MCV}(\mathrm{m} / \mathrm{sec})$} \\
\hline $\mathrm{R}$ & 40 & 40 & 53 & 60 & - & 27 \\
\hline $\mathrm{L}$ & 39 & 48 & 52 & 44 & 32 & 31 \\
\hline $\mathrm{N}$ & $(>52)$ & & $(>52)$ & & $(>48)$ & \\
\hline \multicolumn{7}{|c|}{$\mathrm{DL}(\mathrm{m} / \mathrm{sec})$} \\
\hline $\mathrm{R}$ & 3.5 & 2.8 & 4.5 & 4 & - & - \\
\hline $\mathrm{L}$ & 3.2 & 3 & 3.7 & 3.8 & - & - \\
\hline \multicolumn{7}{|c|}{$\operatorname{SCV}(\mathrm{m} / \mathrm{sec})$} \\
\hline $\mathrm{R}$ & 35 & 43 & 27 & 33 & - & - \\
\hline $\mathrm{L}$ & 38 & 37 & 37 & 34 & - & - \\
\hline \multicolumn{7}{|c|}{ SAP amplitude $(\mu \mathrm{V})$} \\
\hline $\mathrm{R}$ & 2 & 4 & 2 & 2 & - & - \\
\hline $\mathrm{L}$ & 3 & 2 & 3 & 3 & - & - \\
\hline
\end{tabular}

$\mathrm{P}$, proband; $\mathrm{M}$, mother; $\mathrm{R}$, right; $\mathrm{L}$, left; $\mathrm{N}$, normal value; $\mathrm{MCV}$, motor conduction velocity; DL, distal latency; SCV, sensory conduction velocity; SAP, sensory action potential; -, not done. studied by FISH. The breakpoint on chromosome 17 in both patients lies within exons 1 a to 3 of the PMP22 gene. ${ }^{11}$

The proband is a 24 year old male referred to our clinic for molecular analysis to confirm the clinical diagnosis of HNPP. The mother confirmed delayed milestones during infancy, followed by clumsiness and difficulties with running and schooling during childhood and adolescence. At the age of 21 , he had two episodes of numbness and muscular weakness of the left arm following compression while sleeping and weight lifting, without full recovery. Clinical examination showed distal muscle atrophy and weakness of the left arm involving the long distal extensors of the upper limb, the abductor of the thumb, and the supinator of the arm. He was able to walk on his toes and heels and had normal reflexes. No other signs of muscle weakness were noted. Nerve conduction studies showed delayed and reduced sensory action potentials with prolonged motor latencies and slow motor conduction velocities (table 1). Clinical and electroneurographic studies were also carried out in the parents and his twin sister. The mother was clinically asymptomatic, although she reported episodes of paraesthesias with complete recovery involving the upper limbs. Electroneurographic findings were consistent with peripheral neuropathy (table 1) and the diagnosis of HNPP was established in the family. No other members were affected.

Chromosome spreads were obtained from peripheral blood of each patient and a G banding karyotype was performed. Conventional cytogenetics showed the presence of a reciprocal translocation between chromosomes 16 and $17(\mathrm{t}(16 ; 17)(\mathrm{q} 12 ; \mathrm{p} 11.2))$. FISH analysis was performed as described elsewhere ${ }^{18}$ using YAC $181 \mathrm{g9}$ (CEPH) and cosmids c49-E4 (GDB 437232) and c103-B11 (GDB 437233) (both cosmids kindly provided by Dr P I Patel) as probes. FISH analysis showed that YAC 181g9, which encompasses marker D17S122 to marker D17S879 and contains $P M P 22$, crossed the translocation breakpoint. FISH with cosmids c49-E4 and c103-B11 showed that the breakpoint was within cosmid c49-E4, which contains the genomic region encoding the first three exons of the PMP22 gene (fig 1). Therefore, we concluded that the $P M P 22$ gene $^{11}$ is interrupted in these two patients with the HNPP phenotype.

This is the first case of HNPP being caused by a reciprocal translocation that interrupts the PMP22 gene. Cytogenetic studies and FISH confirmed the diagnosis in the patient. The two cases presented here not only confirm that the HNPP phenotype was the result of the interruption of the PMP22 gene, but also show the variable penetrance of the phenotype in two related patients carrying the same mutation. It is therefore unlikely that other genes within the commonly deleted region have contributed to the phenotype. This suggests that modifiers in other genomic regions are involved in the clinical variability of peripheral neuropathies.

The authors would like to thank Dr P I Patel for providing cosmids c49-E4 and c103-B11. This work was supported in part by Servei Català de la Salut and the Generalitat de Catalunya/CIRIT/1997/SGR/00085 grant.

MARGA NADAL * ALBERTO VALIENTE† ANNA DOMENECH* MELANIE PRITCHARD ${ }^{\star} \ddagger$ XAVIER ESTIVILL ${ }^{\star}$ MARIA ANTONIA RAMOS-ARROYO $\dagger$

${ }^{\star}$ Centre de Genètica Mèdica i Molecular-IRO, Institut de Recerca Oncologica, L'Hospitalet de Llobregat, Avenida Castelldefels km 2.7, 08907 Barcelona, Spain †Servicio de Genética, Hospital Virgen del Camino, Pamplona, Spain Correspondence to: Dr Estivill, estivill@iro.es

$\ddagger$ Present address: Centre for Functional Genomics and Human Disease, Monash University Medical School, Clayton, Victoria, Australia 

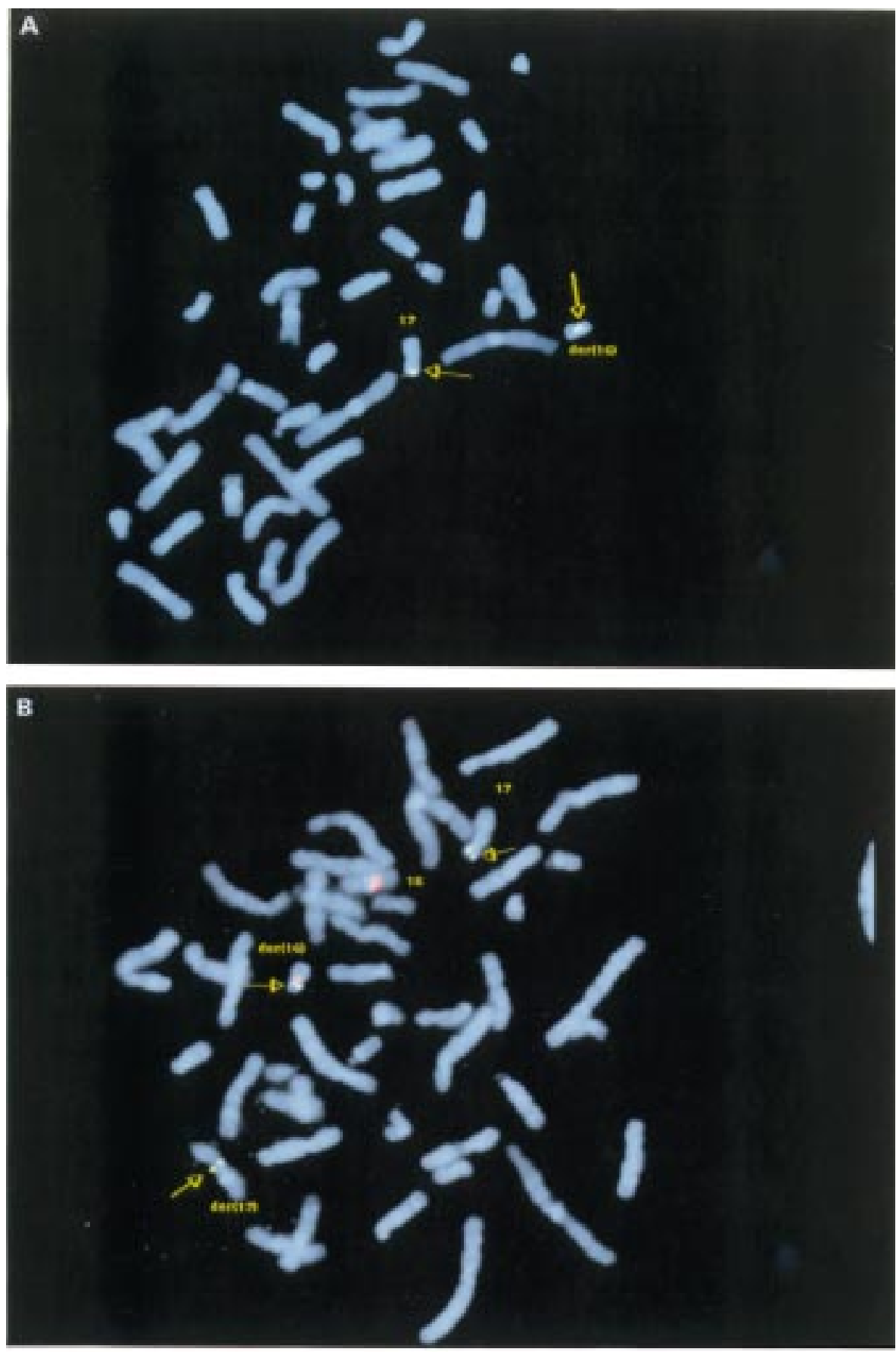

C

PMP22
Cosmids
$049 . E 4\{41.5$ bb $\}$
c103-B11 [45 kb)

5

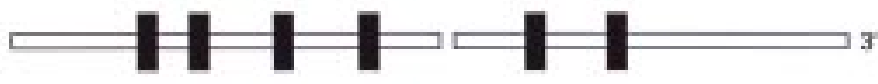

Exons

1A $1 \mathrm{~B}$

2

3

45

t(16;17) $\mathrm{Kq} 12 ; 11.2$

Figure 1 Hereditary neuropathy with liability to pressure palsies (HNPP) resulting from a t(16;17) (q12;p11.2) reciprocal translocation. (A) FISH with cosmid c103-B11 shows signals on chromosomes $17 p 11.2$ and der(16) and does not cross the breakpoint. (B) FISH with cosmid c49-E4 (green) shows signals on chromosomes 17p11.2, der(16), and der(17), indicating that this cosmid crosses the breakpoint and that the PMP22 gene is interrupted by the reciprocal translocation. Probe D16Z1 (red) hybridises to the centromeric region of both chromosome 16 and der(16) (C) Schematic representation of the genomic region encompassing the PMP22 gene, indicating the t(16;17) (q12;p11.2) breakpoint (arrow). 
1 De Jong JGY. Over families met hereditarie disposite tot het optrten van neuritiden, gecorreleard met migraine. Psychiatr Neurol 1947;B1.50:60-76.

2 Madrid R, Bradley WG. The pathology of neuropathies with focal thickening of the myelin sheath (tomaculous neuropathy): studies on the formation

3 Oda K, Miura H, Shibasaki H, et al. Hereditary pressure-sensitive neuropathy: demonstration of 'tomacula' in motor nerve fibers. F Neurol Sci 1990;98:139-48

4 Chance FP, Alderson M, Leppig KA, et al. DNA deletion associated with hereditary neuropathy with liability to pressure palsies. Cell 1993;72:14351.

5 Pareyson D, Taroni F. Deletion of the PMP22 gene in hereditary neuropathy with liability to pressure palsies. Curr Opin Neurol 1996;9:348-54.

6 Nelis E, Van Broeckhoven C. Estimation of the mutation frequencies in Charcot-Marie-Tooth disease type 1 and hereditary neuropathy with liability to pressure palsies: a European collaborative study. Eur $\mathcal{F}$ Hum Genet 1996;4:25-33.

7 Pentao L, Wise CA, Chinault AC, Patel PI, Lupski JR. Charcot-MarieTooth disease type 1A duplication appears to arise from recombination at repeat sequences
$1992 ; 2: 292-300$.

8 Lupski JR, Montes de Oca-Luna R, Slaugenhaupt S, et al. DNA duplication associated with Charcot-Marie-Tooth disease type 1A. Cell 1991;66:21939.

9 Valentijn LJ, Baas F, Wolterman RA, et al. Identical point mutations of PMP-22 in Trembler-J mouse and Charcot-Marie-Tooth disease type 1A. Nat Genet 1992;2:288-91.

10 Roa BB, Garcia CA, Suter U, et al. Charcot-Marie-Tooth disease type 1A. Association with a spontaneous point mutation in the PMP22 gene. $N$ Engl f Med 1993;329:96-101.
11 Suter U, Snipes J, Schoener-Scott R, et al. Regulation of tissue-specific expression of alternative peripheral myelin protein-22 (PMP22) gene tranexpression of alternative peripheral myelin protein-22 (PMP
scripts by two promotors. $\mathcal{F}$ Biol Chem 1994;269:25795-808.

12 Nelis E, Haites N, Van Broeckhoven C. Mutations in the peripheral myelin genes and associated genes in inherited peripheral neuropathies. Hum Mutat 1999;13:11-28.

13 Nicholson GA, Valentijn LJ, Cherryson AK, et al. A frame shift mutation in the PMP22 gene in hereditary neuropathy with liability to pressure palsies. Nat Genet 1994;6:263-6.

14 Young P, Wiebusch H, Stögbauer F, Ringelstein B, Assmann G, Funke H. A novel frameshift mutation in PMP22 accounts for hereditary neuropathy with liability to pressure palsies. Neurology 1997;48:450-2.

15 Taroni F, Botti S, Sghirlanzoni A, Botteon G, DiDonato S, Pareyson D. A nonsense mutation in the PMP22 gene in hereditary neuropathy with liability to pressure palsies (HNPP) not associated with the $17 \mathrm{p} 11.2$ deletion. Am f Hum Genet Suppl 1995;57:A229.

16 Haites NE, Nelis E, Van Broeckhoven C. 3rd workshop of the European CMT consortium: 54th ENMC international workshop on genotypephenotype correlations in Charcot-Marie-Tooth disease type 1 and hereditary neuropathy with liability to pressure palsies, Naarden, The Netherlands. Neuromusc Disord (in press).

17 Bort S, Nelis E, Timmerman V, et al. Mutational analysis of the MPZ, PMP22 and Cx32 genes in Charcot-Marie-Tooth disease and hereditary neuropathy with liability to pressure palsies patients with Spanish ancestry. Hum Genet 1997;99:746-54

18 Nadal M, Moreno S, Pritchard MA, Preciado MA, Estivill X, RamosArroyo MA. Down syndrome: characterisation of a case with partial trisomy of chromosome 21 owing to a paternal balanced translocation (15; 21)(q26;q22.1) by FISH. $\mathcal{f}$ Med Genet 1997;34:50-4. 